\title{
Paisajes infantiles. La infancia como constructora de un imaginario urbano
}

\author{
Esther Mayoral-Campa ${ }^{1}$ | Melina Pozo-Bernal ${ }^{2}$ | Cristóbal Miró-Miró ${ }^{3}$
}

Recibido: 11-12-2020 | Versión final: 08-07-2021

Resumen

\begin{abstract}
El presente artículo desarrolla un entretejido de experiencias vinculadas a la infancia englobadas bajo la idea de paisajes infantiles, con el fin de visibilizar la enorme influencia que la visión infantil ha tenido y sigue teniendo en los procesos de generación o transformación urbana. Estos paisajes analizados apuestan por situar a la infancia en el centro de la reflexión urbana, reclamándola como agente transformador de la ciudad, frente al racionalismo extremo de la sociedad actual. Podemos decir que los paisajes infantiles son aquellas experiencias o acciones que tienen a la infancia como referente en diferentes aspectos. En primer lugar, se analizan propuestas que, inspiradas en el modo de hacer infantil, ofrecen estrategias alternativas para la generación de nuevos paisajes urbanos. En segundo lugar, se analizarán algunos espacios específicos destinados a la infancia que surgieron al detectar que el espacio público adulto no estaba adaptado a niñas y niños, y que generaron paisajes propios y reconocibles para la comunidad. En tercer lugar, se analizan propuestas o acciones que proponen a niñas y niños como agentes transformadores del espacio urbano, con capacidad crítica y propositiva. Estos paisajes infantiles serán analizados desde la arquitectura, desde sus propias características intrínsecas, la topografía, los límites, los elementos que los constituyen, los recorridos que permiten, el encuadre o marco de actuación, y quiénes son los observadores y usuarios de los mismos, con el fin de recuperar de ellos estrategias sugerentes para futuras actuaciones sobre el paisaje urbano.
\end{abstract}

Palabras clave: Paisaje infantil; patios de recreo; participación ciudadana

Citación

Mayoral-Campa, E. et al. (2021). Paisajes infantiles. La infancia como constructora de un imaginario urbano. ACE: Architecture, City and Environment, 16(47), 9945. DOI: http://dx.doi.org/10.5821/ace.16.47.9945

\section{Children's landscapes. The childhood as builder of an urban imaginary}

Abstract This article develops a series of experiences related to childhood, encompassed under the idea of children's landscapes. The goal is to make visible the enormous influence that children's vision has had and continues to have on the processes of urban generation or transformation. The analysis of these landscapes aims to place childhood at the centre of urban debate, understanding it as a transforming agent of the city, against the extreme rationalism of today's society. We can say that children's landscapes are those experiences or actions that have childhood as a reference in different aspects. In the first place, the article examines proposals that, inspired by children's behaviours and practices, offer alternative strategies for the generation of new urban landscapes. Secondly, some specific spaces destined for childhood will be analysed. Particularly, the examined spaces are those that arose when detecting that the adult public space was not adapted to children and that generated their own and recognizable landscapes for the community. Third, this research examines proposals or actions that present children as transforming agents of urban space, with critical and proactive capacity. These children's landscapes will be analysed from architecture, from their own intrinsic characteristics, topography, the limits, the elements that constitute them, the routes they allow, the framing or framework of action. It will also examine who are the observers and users of them, in order to recover from them suggestive strategies for future actions on the urban landscape.

Keywords: Children's landscape; playgrounds; citizen participation

${ }^{1}$ Doctora Arquitecta, profesora Contratada Doctora del Departamento de proyectos Arquitectónicos de la ETSAS (ORCiD: 0000-0003-2085-7020, Scopus Author ID: 57198811005, WoS ResearcherID: J-8346-2018), ${ }^{2}$ Doctora Arquitecta, Investigadora del grupo PAIDI HUM-789 de la Universidad de Sevilla (ORCiD: 0000-0002-8121-534X, Scopus Author ID: 57198815474, WoS ResearcherID: J-8325-2018), ${ }^{3}$ Doctor Arquitecto, Profesor asociado del Departamento de Expresión Gráfica de la ETSAS (ORCiD: 0000-0002-0492-6025, WoS ResearcherID: AAT-58322021). Correo de contacto: esthermc@us.es 


\section{Paisajes infantiles}

"No podemos confiar nuestros intereses arquitectónicos a un pequeño grupo de hombres instruidos, encargarles buscar, descubrir, moldear el entorno donde tendremos que vivir y maravillarnos de percibirlo como una cosa bien hecha; esto nos concierne, por el contrario, a nosotros mismos, a cada uno de nosotros, que debe vigilar y custodiar el justo ordenamiento del paisaje terrestre, cada uno con su espíritu y sus manos, en la medida que le concierna" (Morris, 1908, p. 213).

En ese devenir que ha caracterizado el siglo XX en la transformación de la idea de paisaje -la multiplicidad de miradas, los cambios en la naturaleza de lo observado, la ruptura de límites y los cambios en el observador, de estático a dinámico-, la mirada del niño ha sido esencial en la construcción de un imaginario urbano alternativo. Su actitud desprejuiciada, la forma de instalarse en el presente, la imaginación, la experimentación lúdica como estrategia de comprensión del entorno, la reutilización alternativa de objetos y espacios, o la puesta en valor de lo banal, han sido valores en alza en casi todas las vanguardias del pasado siglo (Figura 1).

\section{Figura 1. Fotomontaje. Paisajes infantiles, 1}

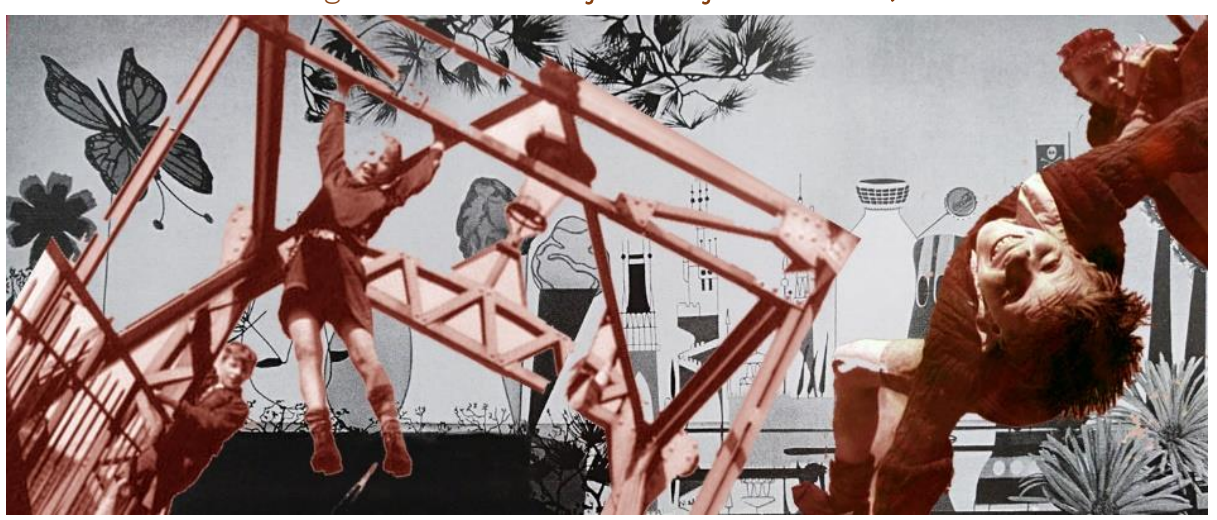

Fuente: Elaboración propia. Fotomontaje realizado con Park of Pleasure (Nigel Ladislav Sutnar, 1952) y varias fotografías sin título de Chisenhale Road Series (Nigel Henderson, 1951).

Durante el siglo XX, hasta nuestros días, han convivido dos formas de entender el mundo de la infancia. Por un lado, niñas y niños tienen una posición cada vez más central en la sociedad, que se ocupa de forma preferente de su protección, su control y sus estudios. Esta visión de la infancia entiende al niño como "la potencialidad máxima del progreso o la decadencia de la sociedad futura, pero a la vez niños y adolescentes suelen resultar invisibles u opacos, en cuanto a sus interpretaciones de la realidad y a su capacidad de influir en sus entornos" (Vergara, Peña, Chávez y Vergara, 2013). Por otro lado, está la visión del niño como entidad social y cultural propia, que ha estado presente de forma transversal a lo largo de los dos últimos siglos y que, de forma tangencial, nunca predominante, ha tenido una enorme influencia sobre el panorama artístico y arquitectónico. Si en la primera visión el dominio físico y espacial del niño es la casa y la escuela como trasunto de la familia y la educación, en esa segunda mirada es la ciudad, el ambiente urbano, el lugar donde se ha reivindicado a ese niño como sujeto desde campos como la pedagogía, la sociología, el arte o la arquitectura.

Este artículo establece un entretejido de experiencias vinculadas a la infancia bajo el nombre de "Paisajes infantiles"(Figura 1), que recorren la evolución que ha supuesto el papel del niño en relación con la transformación del concepto de paisaje. Propuestas antecedentes de las acciones de empoderamiento de la infancia que se están llevando a cabo en la actualidad, y que proponen al niño como testigo y agente transformador especialmente sensible para la generación de espacios urbanos

ACE, 16 (47) CC BY-ND 3.0 ES | UPC Barcelona, España | Paisajes infantiles. La infancia como constructora de un imaginario urbano. DOI: http://dx.doi.org/10.5821/ace.16.47.9945 
de calidad'1 (Ligtelijn y Strauven, 2008). Estos paisajes analizados apuestan, en definitiva, por situar a la infancia en el centro de la reflexión urbana, reclamándolo como usuario transformador de la ciudad, frente al racionalismo extremo de la sociedad actual, en una actitud que ya reclamaba William Morris en el siglo XIX y que reivindicaba la responsabilidad colectiva que tiene la sociedad en la construcción del entorno urbano.

De una manera explícita, en la exposición "The Century of The Child”, celebrada en el MoMA de Nueva York en $2012^{2}$ (Kinchin y O'Connor, 2012), queda recogido este interés por el modo infantil de relacionarse con el mundo. Desde una perspectiva multidisciplinar, esta exposición analiza el papel fundamental adquirido por la infancia en el pasado siglo y cómo este transformó sustancialmente el diseño contemporáneo. La muestra ofrece un recorrido por el modo de acercamiento infantil a la realidad desde diferentes disciplinas, como la pedagogía, el arte, el cine, la arquitectura y el diseño, y plantea las repercusiones que esto tuvo también en la construcción del paisaje urbano, al proponerlo como instrumento de transformación. Esta reflexión es el origen de esta investigación.

Estos planteamientos iniciales que tuvieron en cuenta a la infancia dieron pie a estrategias de actuación sobre el paisaje que han llegado hasta nuestros días. En este artículo se recorren estas estrategias desde tres registros diferentes tratando de definir la idea de paisaje infantil a través de situaciones, experiencias o acciones que tienen a la infancia como referente. Estos tres registros ya estaban recogidos por parte del escritor anarquista Colin Ward en su libro The child in the city, donde defiende que la ciudad es un laboratorio de aprendizaje para niñas y niños y que su particular forma de experimentar el espacio abre campos de investigación para mejorar la relación entre estos habitantes esenciales y el entorno urbano donde desarrollan su vida (Ward, 1978), una reflexión que fundamenta en la observación de cómo niñas y niños ven y experimentan la ciudad y en el propio recuerdo del niño ${ }^{3}$ que él fue. Una experiencia del espacio que genera una memoria en el habitante esencial para construir una identidad urbana y un modelo de ciudad.

El primer acercamiento en el punto 2, "Miradas inspiradas en la infancia", se relaciona con la idea del niño como inspiración. Bajo dos epígrafes - el 2.1, "La exploración activa de la ciudad. El globo rojo" y el 2.2, "Recorrer es aprender" - se reflexiona sobre propuestas artísticas o cinematográficas que, inspiradas en el modo de ver infantil, ofrecen estrategias alternativas para la generación de nuevos paisajes urbanos.

En segundo lugar, en la sección 3, "Paisajes específicos destinados a la infancia", se analizan algunos enfoques particulares llevados a cabo en el diseño de espacios urbanos específicos destinados a la infancia. Son lugares que surgieron al detectar que el espacio público adulto no estaba adaptado a la infancia y que generaron paisajes propios y reconocibles para la comunidad. Estos se desarrollan en cuatro epígrafes: 3.1, "Translaciones sobre el juego y el movimiento"; 3.2, "Playgrounds como espacio público. Del objeto al paisaje"; "3.3, Junk playgrounds o el ensayo de la ciudad ideal” y 3.4, "Paisajes infantiles como paisajes de consumo".

\footnotetext{
${ }_{1}^{1}$ Autores como Jane Jacobs, Aldo van Eyck o más recientemente Jan Gehl, con libros como Ciudades para la gente, han venido reclamando una ciudad más humana para aquellos grupos sociales más desfavorecidos por el sistema, mujeres, niñas, niños y ancianos. Todos estos autores señalan a la infancia como indicadores de calidad del entorno urbano, como así recoge la célebre frase de Van Eyck recogida en su ensayo The Child, The City and The Artist. "Si [las ciudades] no están pensadas para los niños, tampoco están pensadas para los ciudadanos. Si no las pensamos para los ciudadanos, no son ciudades".

${ }^{2}$ La exposición desarrollada en el MoMA analiza el interés de artistas, diseñadores, políticos, arquitectos y educadores por una nueva visión del niño a través de siete registros temporales, con una temática transversal a ese periodo. Estos son: New Century, New Child, New Art (19001910); Avant-Garde Play Time (1910-1930); Light, Air, Health (1920-1930); Children and the Body Politic (1920-1940); Regeneration (19401960); Power Play (1960-1990); Designing Better Worlds (1960-2000). Para este artículo interesa particularmente el apartado Regeneration, ya que abarca un periodo en el que la reflexión sobre el niño y la ciudad se hace especialmente fecunda.

${ }^{3}$ En el prólogo de su libro, Ward citaba a Margaret Mead con esta frase: "Está bien pensar en el niño mientras recordemos que el niño no existe. Existen niños. Cada vez que los agrupamos en una misma categoría, perdemos algo". Recuperando esa reflexión sobre "el niño", se aprecia que es un término que a menudo generaliza y reduce a un tipo genérico y único una realidad compleja. Esta engloba la singularidad de cada una de las individualidades que la conforman. Naturalezas diferenciadas por la edad, por el género, por la procedencia social o por la nacionalidad. En este artículo, por tanto, trataremos de resolver esta cuestión asumiendo que la infancia es el término que engloba a niñas y niños desde su nacimiento hasta la adolescencia, que, además, incluye todos los géneros y que se acota a un habitante urbano y contemporáneo. Se tratará de, en la medida de lo posible, utilizar un lenguaje inclusivo, reconociendo el papel dentro de la ciudad de niñas y niños.
}

ACE, 16 (47) CC BY-ND 3.0 ES | UPC Barcelona, España | Paisajes infantiles. La infancia como constructora de un 
En tercer lugar, en el punto 4, "El niño como agente transformador de la ciudad", se analizarán propuestas o acciones que desde distintas disciplinas proponen al niño como agente transformador del espacio urbano, con capacidad crítica y propositiva. Por último, se desarrollarán las conclusiones.

Esos paisajes infantiles serán analizados desde la arquitectura, entendida esta como metodología de investigación (Llorca J., 2021), a través de sus características intrínsecas, como la topografía, los límites del espacio, los elementos que lo constituyen, los recorridos que permiten, el encuadre o el marco de actuación, así como considerando quiénes son los observadores y los usuarios de los mismos, acciones que en muchos casos han relacionado infancia y ciudad.

\section{Miradas inspiradas en la infancia. Recorrer es aprender}

A lo largo del siglo XX, numerosos artistas han reclamado la recuperación de la actitud infantil para abordar el arte. Muestra de ello es la exposición celebrada en el Museo Cantonal de Arte de Lugano en 2005 "Los niños terribles", donde se recogía la influencia de la forma de expresión infantil en pintores como Klee, Picasso, Miró o Jawlensky. Estos artistas, sobre todo $\mathrm{Klee}^{4}$ (Gisboure, Kukudielka y Djerassi, 2008), buscaron nuevas formas artísticas en el dibujo de niñas y niños. Otras vanguardias artísticas, como los futuristas, ven en el niño la promesa de un nuevo futuro (Sánchez Llorens, 2015), mientras los dadaístas y los situacionistas se inspiraron en los errabundeos infantiles para registrar en la ciudad motivos artísticos o, por último, el grupo CoBrA (Mayoral-Campa, 2014) trató de reproducir sus mecanismos creativos y colaboró con ellos en algunas de sus obras. En general, es una mirada positiva hacia la infancia que hunde sus raíces en los planteamientos de Rousseau ${ }^{5}$ sobre la educación, y que exaltan la naturaleza peculiar, inocente, libre, virtuosa e imaginativa del niño.

Esa mirada desde el arte hacia la naturaleza del niño será esencial en una nueva forma de aproximación al paisaje urbano, que reclama una actitud activa en su conocimiento a través del movimiento y una incorporación del contexto como lugar para el aprendizaje, el entorno natural primero y, más tarde, la ciudad. Podemos reconocer estas actitudes hasta nuestros días en acciones como el laboratorio de arte urbano Stalker, de Francesco Careri ${ }^{6}$, o las acciones sobre el paisaje de la red Jane's Walk, que a través del paseo por las ciudades reivindica las ideas de la urbanista y activista Jane Jacobs?. Para esta: "En sí misma, una acera urbana no es nada. Es una abstracción. Solo tiene significado en conjunción con los edificios y otros servicios anejos a ella o anejos a otras aceras próximas. Lo mismo podríamos decir de las calles, en el sentido de que sirven para algo más que llevar el tráfico rodado en su cauce. Las calles y sus aceras, los principales lugares públicos de una ciudad, son sus órganos más vitales. ¿Qué es lo primero que nos viene a la mente al pensar en una ciudad? Sus calles. Cuando las calles de una ciudad ofrecen interés, la ciudad entera ofrece interés; cuando presentan un aspecto triste, toda la ciudad parece triste" (Jacobs, 2011, p. 55). Todas

\footnotetext{
${ }^{4}$ Paul Klee es uno de los principales exponentes de esos artistas que buscan el niño que fueron para la expresión de nuevas formas de arte, cuestión que también llevó a su faceta pedagógica en la Bauhaus. La exposición "La infancia en la edad adulta" recoge parte de estas reflexiones. 5 Jean-Jacques Rousseau (1712-1778) es un escritor, filósofo y pedagogo nacido en Francia y cuyo contexto cultural es la llustración. Con su libro Emilio. O de la educación (1762) modificará para siempre la idea sobre la infancia y la forma en que debe ser educada. Sus ideas se basan en la creencia en la bondad de los niños y los hombres, y en que para llegar a tener ciudadanos completos hay que transformar la educación. Defiende que esta debe dejar de ser una instrucción basada en la disciplina y centrarse en los intereses de los niños. Él reconoce en la naturaleza del niño unas virtudes esenciales para crear un hombre nuevo. Su curiosidad, su imaginación, la experimentación del entorno, se convertirán, desde la aparición de este escrito, en una constante de todas las pedagogías que han centrado en la naturaleza de la infancia su reflexión.

${ }^{6}$ El recorrido es también elegido por Careri para la búsqueda de posibles estrategias de actuación urbana, necesaria para el acercamiento a una composición compleja como la ciudad contemporánea. En el laboratorio de arte urbano Stalker propuso la interacción con los habitantes y el errabundeo por los espacios vacíos de la ciudad, ya que considera imprescindible el análisis de las "partes ocultas" de la urbe, de ese nuevo paisaje creado por nuevas formas de movilidad.

${ }^{7}$ Jane's Walk es una red internacional que agrupa a activistas urbanos que a través del paseo ponen en valor las ciudades y reivindican la figura de Jane Jacobs. En España esta iniciativa tiene una enorme acogida, estando representadas 20 ciudades del ámbito nacional. Janes Walk [en línea] [fecha de consulta: 10 febrero 2020]. Disponible en: https://janeswalk.org/
} 
estas acciones redescubren ese nuevo paisaje creado por nuevas formas de movilidad y proponen la reutilización de vacíos y la superposición de modos de habitar, propios de una ciudad que se modifica constantemente.

\subsection{La exploración activa de la ciudad. El globo rojo}

"El flâneaur es subversivo. Subvierte la multitud, subvierte la mercancía y la ciudad, así como sus valores..., subvierte la soledad, la velocidad, la especulación y el consumo... Entre la multitud todos tienen prisa, todos quieren ir rápido y, a la vez, se ven trabados. El flâneaur, en cambio, no tiene que ir ni aquí ni allá... El flâneaur ralentiza su cuerpo, pero sus ojos van y vienen sin cesar, y su mente se asombra de mil cosas a la vez" (Gros, 2014, pp. 188-189).

La película El globo rojo (1956), de Lamorisse (Figura 2), bien podría estar describiendo a ese flâneaur del que habla la cita y que hace referencia a la figura descrita por Walter Benjamin. Benjamin utilizó como inspiración para ese personaje los escritos de Baudelaire sobre el spleen de París en Las flores del mal, y de la misma forma Lamorisse nos sumerge en las calles de esta ciudad, París, como símbolo de la ciudad antimoderna tan criticada por el movimiento moderno.

La película se inscribe en esa construcción del paisaje que pone el foco en la ciudad, incorporando una consideración radical de lo urbano, así como de la naturaleza y la posición del observador: un niño en movimiento.

Figura 2. Cartel de la película El globo rojo, Albert Lamorisse, 1956

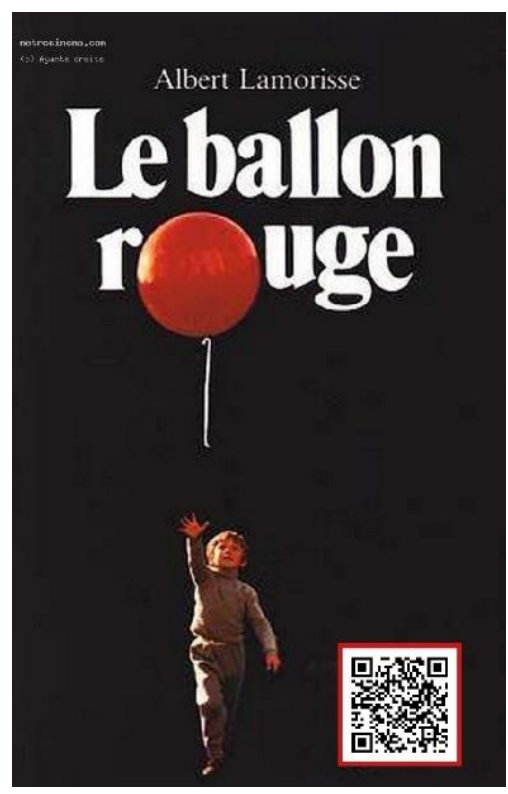

Fuente: Elaboración propia.

Nota: Código QR para visualizar la película

De esta forma, Lamorisse parece querer condensar en imágenes parte de los posicionamientos culturales que, en el periodo de posguerra, comprendido entre los años 50 y 70 del pasado siglo, fueron claves para un cambio de paradigma en torno a la consideración de la ciudad. Desde los futuristas de Tristan Tzara y los dadaístas de André Breton hasta los artistas de Land Art se produce una incorporación paulatina del movimiento y la acción infantil al hecho artístico. Esto incidirá tanto en las formas de recorrer y en la actitud del que recorre como en los lugares que se recorren, reconfigurando el panorama de actuación del entorno urbano.

ACE, 16 (47) CC BY-ND 3.0 ES | UPC Barcelona, España | Paisajes infantiles. La infancia como constructora de un imaginario urbano. DOI: http://dx.doi.org/10.5821/ace.16.47.9945 
Para el director, la ciudad es un territorio continuo que lleva al espectador a ser testigo de la vida urbana, en una exaltación de lo cotidiano, de lo banal, que ya reclamaron los dadaístas en sus excursiones por París. Así como ellos, Lamorisse muestra París no desde la imagen convencional perteneciente al imaginario colectivo, donde su dimensión monumental es protagonista, esto solo es una intuición en una imagen lejana y brumosa en la presentación de la ciudad en la primera escena de la película. Por el contrario, el director nos ofrece un repertorio de lugares banales, calles anónimas estrechas y anchas, transitadas y vacías, escaleras urbanas, solares abandonados, mercadillos, el patio del colegio donde el pequeño protagonista se educa, lugares donde el vacío predomina sobre el objeto, lo ordinario frente a lo extraordinario, lo periférico frente a lo central (Figura 3).

Figura 3. Montaje de fotogramas de la película El globo rojo
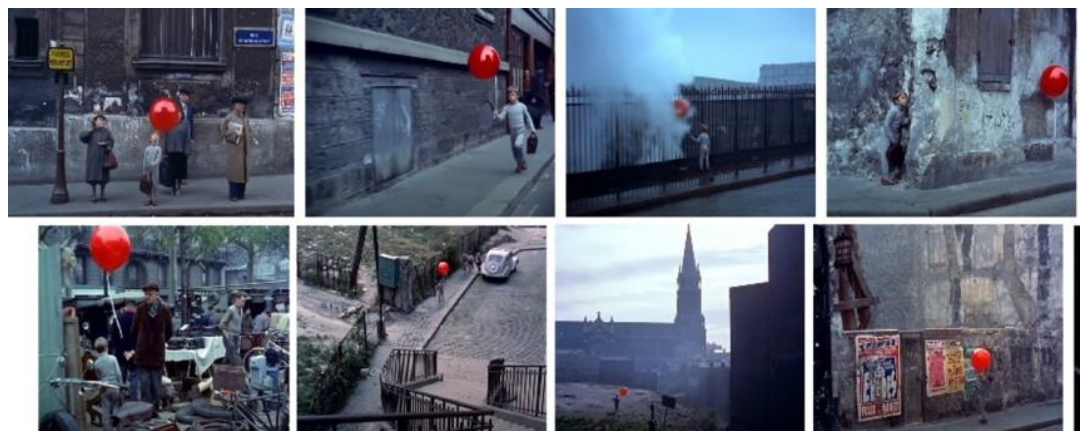

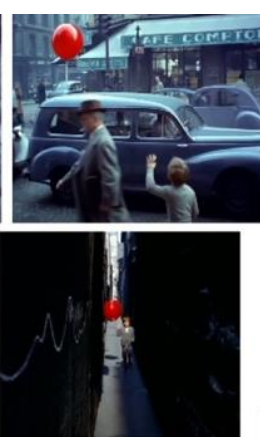

Fuente: Elaboración propia.

La ciudad en la película también es un singular espacio de libertad, nunca se muestran espacios interiores, e incluso cuando el punto de vista desde el que se hace la toma es interior, lo que se muestra es la vida urbana, a través de un escaparate, tal y como hacía Robert Doisneau en su serie fotográfica "La vitrine de Romi" (1948) o "La vitrine de Noel” (1947) (Figura 4).

Figura 4. De izquierda a derecha “La vitrine de Noel”, Robert Doisneau, 1947. Pascal en la pastelería película el globo
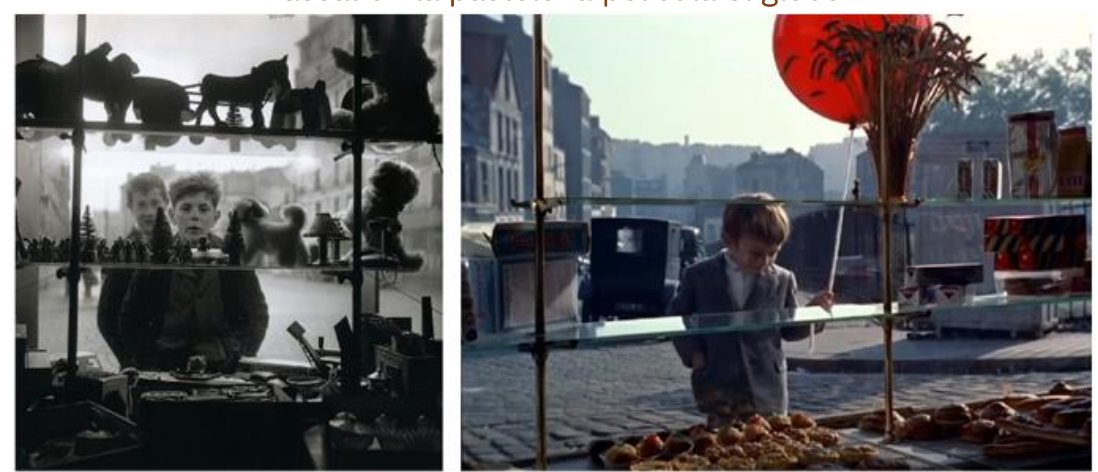

Fuente: Atelier Robert Doisneau. Fotograma de la película. Elaboración propia.

Ese contexto urbano construye el único escenario posible para una relación de amistad entre un niño y un globo, trama que se desarrolla en la primera parte de la película. Esa relación inverosímil e incomprendida siempre entra en conflicto en los espacios interiores: en el tranvía, la iglesia, la casa o la escuela del protagonista. La relación del niño y el globo también simboliza la subversión de la norma social, la integración de lo diferente, la exaltación de la imaginación, y añade una dimensión surrealista a la consideración del contexto, ampliando su naturaleza de lo real a lo soñado. Un espacio de libertad, único territorio para el juego, que vincula al director de la película con las ideas promovidas por la Internacional Situacionista (Careri, 2009): la ciudad como escenario de reivindicación política y como territorio potencial de expresión para el arte. Esto se escenifica a través

ACE, 16 (47) CC BY-ND 3.0 ES | UPC Barcelona, España | Paisajes infantiles. La infancia como constructora de un 
de la revolución de los globos que muestra la película en su parte final y de las fantásticas imágenes que nos brindan la interacción de estos con la ciudad. No es casual que Pascal, el niño protagonista, trascienda a otra realidad desde ese lugar vacío en el que se eleva sobre los cielos de París como metáfora de su libertad (Figura 5).

La película también introduce otro aspecto esencial de todos esos movimientos artísticos de vanguardia, que consolidaron en la posguerra la acción de "recorrer" como estrategia artística y de aprendizaje. El recorrido entendido como experiencia en sí, el andar como acto de construcción de un nuevo paisaje, una exploración del espacio que modifica su temporalidad, la escala, el punto de vista, superando una lectura bidimensional del contexto, para experimentar una nueva red de lugares. Como dice Gros: "Caminando no se hace nada más que caminar. Pero no tener nada que hacer más que caminar permite recuperar el puro sentimiento de ser, redescubrir la simple alegría de existir, la que constituye la esencia de la infancia. Así, la marcha, al liberarnos de carga, al arrancarnos la obsesión del hacer, nos permite recobrar esa eternidad infantil. Quiero decir que caminar es un juego de niños" (Gros, 2014, pp. 188-189).

Figura 5. Montaje de fotogramas de la película El globo rojo
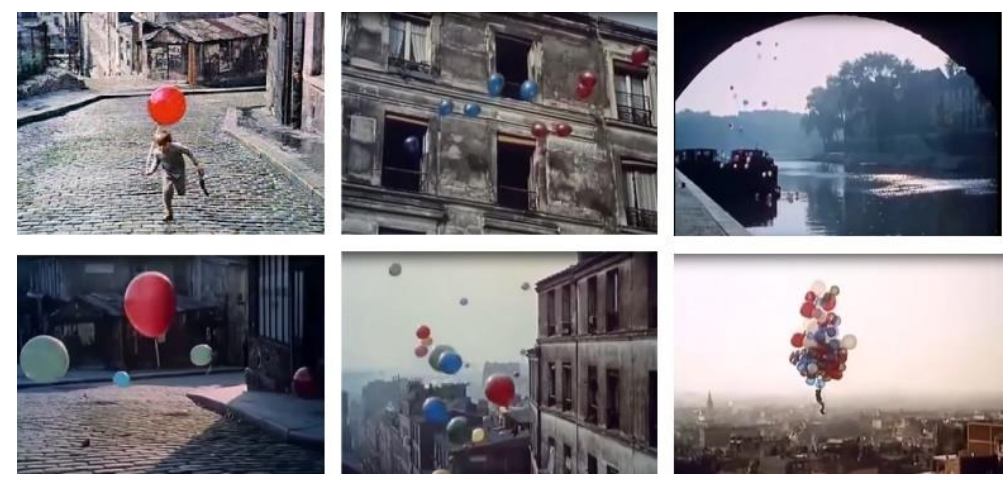

Fuente: Elaboración propia.

El cortometraje de Lamorisse nos habla del poder de la ciudad como instrumento de aprendizaje a través de la invitación lúdica del globo rojo a pasear por la ella.

El movimiento "aleatorio" del globo podría representar esa mirada espontánea, sin prejuicios, con el que niñas y niños disfrutan de la ciudad, de sus espacios abandonados, y que nos descubren en multitud de ocasiones otras realidades latentes, otras estrategias de transformación y aprendizaje. Frente a esto, la escuela masculina de Pascal, un espacio de represión de la imaginación, un lugar lleno de reglas donde adiestrar a los niños. La película reclama ese recorrido que Pascal hace de su casa a la escuela como otra forma de aprendizaje esencial para la formación del niño como adulto crítico (Pozo-Bernal y Mayoral-Campa, 2016).

\subsection{Recorrer es aprender}

Ese nomadismo activo, que desde un punto de vista pedagógico se incorpora a la forma de enseñar y aprender desde el siglo XIX en las metodologías activas de aprendizaje, tiene también un trasunto en el arte. Los límites entre ambos mundos se diluyen, en la medida en que un acercamiento artístico a la realidad es una forma de aprenderla, de captarla y transformarla que tiene lugares comunes con las pedagogías aplicadas en la escuela activa, en todos estos procesos que incorporan el movimiento, la imaginación y la intuición al aprendizaje. Así surgieron los recorridos por la ciudad del señor Hulot y su sobrino, en la película Mi tío (Tati, 1958), que nos hablan de esa actitud inconsciente, de esa experiencia del espacio como exploración, donde el aprendizaje no está al final del camino, sino en la experiencia del recorrido (Figura 6).

ACE, 16 (47) CC BY-ND 3.0 ES | UPC Barcelona, España | Paisajes infantiles. La infancia como constructora de un imaginario urbano. DOI: http://dx.doi.org/10.5821/ace.16.47.9945 
Pero en todas estas manifestaciones, y sobre todo a partir de la Segunda Guerra Mundial, se inicia un camino desde la observación a la acción, y se comienzan a establecer posicionamientos artísticos y sociales frente a la ciudad como crítica al sistema capitalista de posguerra. La Internacional Letrista introduce el concepto psicogeográfico de "deriva", aportando investigaciones sobre los efectos psíquicos que produce el contexto urbano en los ciudadanos. De esta manera, se posicionan contrarios a la interpretación capitalista de la ciudad como producto de consumo. En ese sentido, es ilustrativo el enfrentamiento entre Jane Jacobs y Robert Moses recogido en el documental Citizen Jane: Battle for The City (Tyrmauer, 2017).

Figura 6. Fotomontaje. Paisajes infantiles, 2

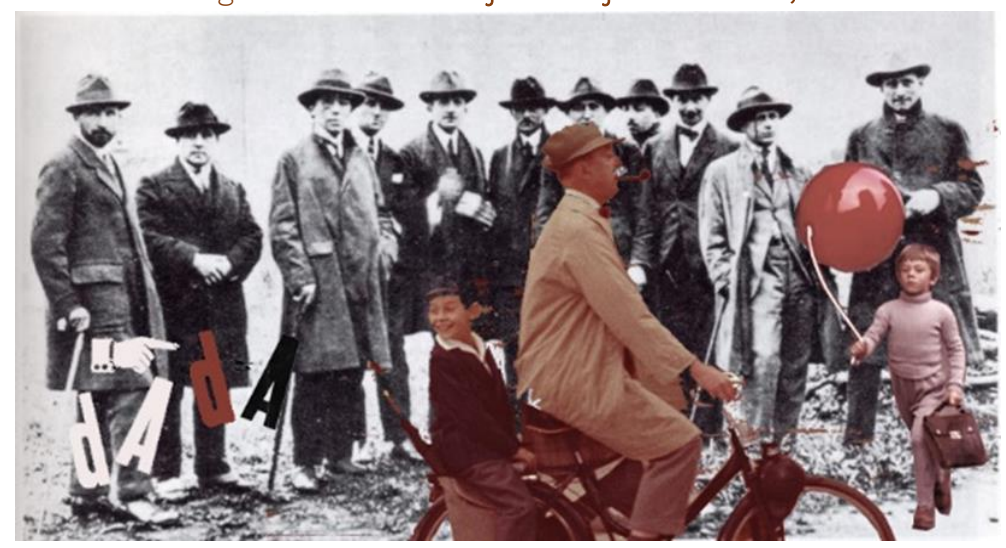

Fuente: Elaboración propia. Fotomontaje realizado con las siguientes imágenes: "Excursión dadá en Saint Julien le Pauvre", película Mi tío, de J. Tati (1958), y película El globo rojo.

Se pasa de una huida del sistema a un compromiso para el cambio, proponiendo la ciudad lúdica, y con ello un uso alternativo del espacio. Habitar es estar en casa en todas partes, es encontrar un espacio seguro y creativo para los ciudadanos. Ideas de ida y vuelta entre pedagogía, arte y arquitectura que se cristalizan en figuras como la de Constant, artista fundador del grupo CoBra e integrante de la Internacional Situacionista, que influenció en gran medida el trabajo urbano realizado por el Team X y Aldo van Eyck. O en un marco temporal más reciente, a su discípulo, el arquitecto Herman Hertzberger o el pedagogo italiano Francesco Tonucci, los cuales también proponen acercamientos similares sobre el uso del entorno urbano como experiencia de aprendizaje.

Este modo infantil de reconocer el entorno no es lineal ni determinado, se propone como deambulación, movimientos o acercamientos que a priori parecen erráticos e insustanciales, pero absorben del entorno una gran cantidad de información y denotan una sensibilidad especial a la hora de registrar la calidad del espacio urbano por la infancia.

En todas estas manifestaciones podemos rastrear al niño como sujeto de la acción de recorrer, ya sea por su actitud respecto al entorno sin convenciones ni prejuicios, por su capacidad de trascender lo real e incorporar lo imaginado a su experiencia vital, por su relectura del mundo a través del juego o por su capacidad para incorporar el territorio en su aprendizaje. En definitiva, movimientos que reivindican a la infancia, su mirada sobre la ciudad como una nueva forma de acercarse a lo urbano.Porque, como decía George Perec, las niñas y los niños se interrogan "por aquello que parece haber dejado de sorprendernos para siempre" (Perec, 2013, p. 15).

\footnotetext{
${ }^{8}$ George Perec (1936-1985) es un escritor francés que reflexiona sobre el espacio doméstico y urbano situando en el centro del discurso la experiencia del habitante y la vida cotidiana como expresión artística. Libros como Especies de espacios, Lo infraordinario o Tentativas para agotar un lugar parisino son una exaltación de lugares comunes que encuentran lo extraordinario en la banalidad de la vida.
}

ACE, 16 (47) CC BY-ND 3.0 ES | UPC Barcelona, España | Paisajes infantiles. La infancia como constructora de un imaginario urbano. DOI: http://dx.doi.org/10.5821/ace.16.47.9945 


\section{Paisajes específicos destinados para la infancia}

En este apartado del artículo se quiere destacar otra referencia esencial en la construcción del paisaje urbano en relación con la figura del niño: la construcción de paisajes específicos urbanos destinados a la infancia. De la construcción de una nueva mirada sobre la ciudad se pasa a detectar y proponer un nuevo programa para la ciudad: los playgrounds. Para ello, de forma sucinta, se traen a colación dos conceptos que ayudan a vincular el paisaje urbano con el aprendizaje infantil: el juego y el movimiento como herramientas para descubrir el entorno en la infancia (Figura 7).

Figura 7. Fotomontaje. Paisajes infantiles, 3

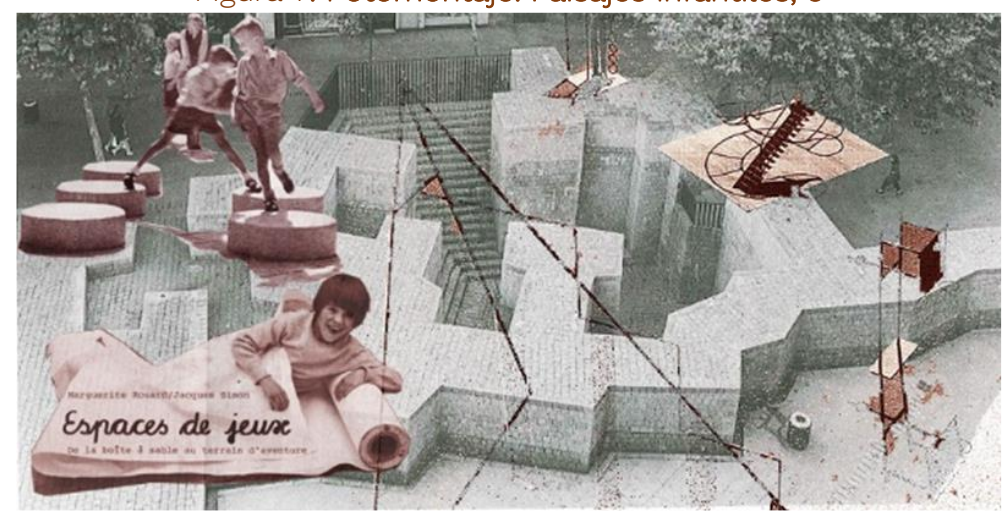

Fuente: Elaboración propia. Fotomontaje realizado con "Niños jugando en los playgrounds", de Aldo van Eyck; plaza de los fueros en Vitoria de Luis Peña Ganchegui y Eduardo Chillida; "Juegos", de Isamu Noguchi, y portada del libro Espaces de jeux, de Jacques Simon.

\subsection{Traslaciones sobre el juego y el movimiento}

El pedagogo Jean Piaget (Muntaner i Guasp, 1988) afirmaba que el conocimiento surge de la interacción entre el individuo y el contexto. Este no surge, por tanto, de un proceso causa-efecto, sino de la relación de dos conceptos: resistencia y adaptación. Las distintas y continuas exposiciones al contexto generan una resistencia genética en el individuo que, poco a poco, y por una necesidad de equilibrios internos, va modificando su estructura interna, adaptándose al medio para sobrevivir. Esta acomodación es la que explicaría el modo de aprendizaje natural del ser humano, como una relación del individuo en movimiento en el entorno. Esta práctica de comunicación a través del movimiento se desarrolla en la infancia a través del juego, que se convierte en un verdadero instrumento de aprendizaje.

Esto quiere decir que el niño construye su propio aprendizaje, aprendiendo desde la acción y el juego, a través de la experiencia directa. La libertad de movimientos para la etapa infantil es entonces indispensable y también el aprendizaje a través el juego, como herramienta de trabajo. Este modo de reconocer el entorno no es lineal ni determinado, es una deambulación, movimiento muy parecido al que realizan los bebés en sus primeros reconocimientos sobre el terreno. Las niñas y los niños parecen inicialmente erráticos e insustanciales, pero absorben del entorno una gran cantidad de información. En el caso infantil, este proceso de aprendizaje se formaliza mediante estas dos acciones entrelazadas: juego y movimiento.

Aunque pedagogos como Rousseau o, ya en el siglo XIX. Froebel, ya avanzaron la importancia del juego, es el filósofo e historiador Huizinga quien ofrece una visión del juego como acción consustancial de la cultura, por lo que se constituye como herramienta de construcción social, incorporando a los aspectos biológicos, psicológicos y etnológicos una nueva dimensión del juego muy interesante para la arquitectura.

ACE, 16 (47) CC BY-ND 3.0 ES | UPC Barcelona, España | Paisajes infantiles. La infancia como constructora de un imaginario urbano. DOI: http://dx.doi.org/10.5821/ace.16.47.9945 
Huizinga traslada al hombre esa actitud inicialmente perteneciente a la infancia, y define al ser como Homo ludens (Huizinga, 2012). El juego es para este autor una acción natural y libre, que ofrece y genera fantasías y las traslada al mundo real, a la vez que ayuda a tener conciencia del entorno. El juego genera igualmente actitudes de competencia que obliga a los individuos a establecer unas reglas y a tener conciencia de unos límites espaciales y temporales y, en definitiva, a mostrar una actitud crítica frente al mismo. Para Huizinga, sin cierta actitud lúdica no es posible la cultura, lo que confiere al juego un carácter primario en la construcción social.

Una vez que se detecta que el juego no es solo un entretenimiento, sino una herramienta de aprendizaje, y se entiende que la ciudad no es un lugar seguro debido a la proliferación de vehículos de motor en los años 50 y 60, es necesario readaptar la ciudad para esta actividad infantil en condiciones de seguridad y protección favorables. Así surgen los playgrounds, el primer espacio público específicamente pensado para la infancia en la ciudad. Se trata de espacios generalmente segregados, acotados físicamente, con elementos lúdicos, que se convierten hoy en estandarizados y homologados, realizados con materiales que apenas permiten su manipulación, y amortiguan cualquier sensación directa con el entorno.

Figura 8. Algunos títulos relacionados con la infancia y el espacio urbano

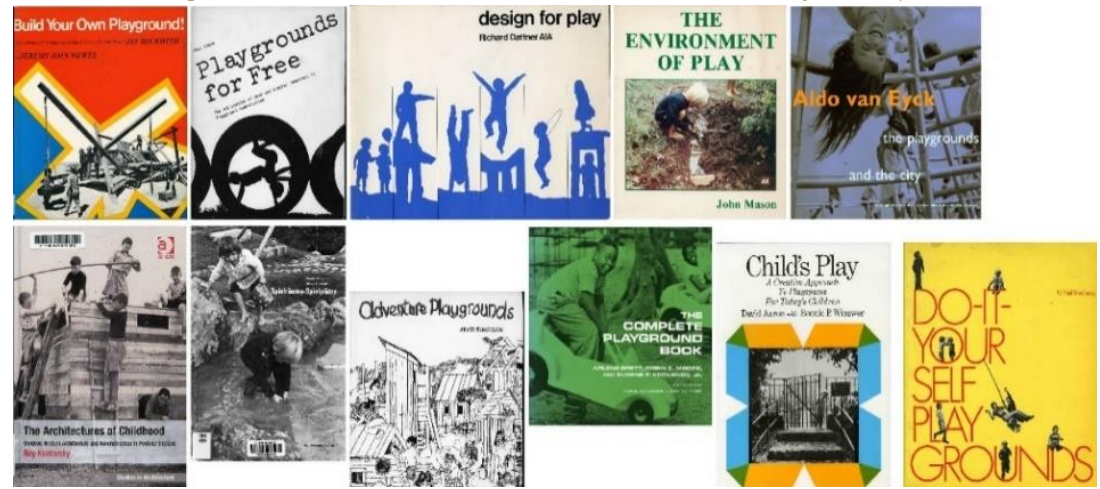

Fuente: sitio web de The Playground Project Architektur für Kinder.

El interés acerca de estos espacios como lugares de experimentación formal y reflexión acerca del papel que el niño debe tener en la ciudad no ha decaído a lo largo de los años, como se puede ver en la numerosa bibliografía existente desde los años 50 del pasado siglo9 (Figura 8). Exposiciones como "Reinventar la plaza" celebrada en el Museo Reina Sofía de Madrid en 2014, o la creación de "Playgrounds, encuentros de arquitectura e infancia" que, aprovechando las sinergias de la exposición antes citada, vienen celebrando desde ese mismo año una serie de encuentros científicos ${ }^{10}$, ponen de manifiesto el interés de la sociedad actual y de la disciplina arquitectónica por la reflexión y la acción en torno al niño y la mejora de su entorno urbano. Numerosos colectivos y estudios de arquitectura multidisciplinares están trabajando en la actualidad en la generación de acciones colectivas en torno a los espacios de juego, ya sean en el espacio público o en los espacios de recreo de colegios. El Globus Vermell o Colllectiu Punt 6, en Cataluña, Cuarto Creciente o Recetas Urbanas, en Andalucía, el colectivo Tipi, en el País Vasco, o el proyecto Lupo, en Galicia, trabajan desde la idea del juego como motor de la educación y de la generación de espacios más inclusivos.

Dentro de toda la casuística de espacios de juego en la ciudad, se analizan en este artículo algunos casos particulares que abandonan la necesidad de una perspectiva funcionalista de protección y control para situarse en posiciones más cercanas a la naturaleza del niño y establecen una singular relación con la ciudad, y que ofrecen particularidades en cuanto a tres ópticas. En primer lugar, los

\footnotetext{
${ }^{9}$ Testigo del interés por parte de la arquitectura acerca de este tipo de espacios es el sitio web de The Playground Project Architektur für Kinder (http://architekturfuerkinder.ch/), que recoge una extensa bibliografía sobre el tema y sobre los autores más relevantes de este tipo de espacios ${ }^{10}$ Proyectos como Ludantia Bienal de Arquitectura e infancia, se hacen eco de la importancia que está adquiriendo la infancia para la disciplina.
} 
espacios urbanos específicos que tienen a niñas y niños como usuarios principales, espacios donde el niño interactúa con el entorno, pero no lo altera. En segundo lugar, los espacios específicos aislados en la ciudad, donde niñas y niños, además de su participación como usuarios, tienen un papel más activo construyendo y trasformando el espacio (Navarro, 2013). Y, en tercer lugar, espacios para las niñas y los niños en los que estos tienen un papel de consumidores, espacios acotados que recrean un mundo de fantasía al margen de la ciudad.

\subsection{Playgrounds como espacio público. Del objeto al paisaje}

Este apartado se va a detener en aquellos playgrounds urbanos que se encuentran integrados en el espacio público de la ciudad, que no ofrecen límites físicos de separación, sino ámbitos de actuación alrededor de sus elementos lúdicos o sobre el pavimento soporte. Estos elementos lúdicos no son solo funcionales ni son utilizados específicamente por niñas y niños, sino que se incorporan mediante diseños sencillos al mobiliario urbano de la ciudad para ser usados por todos. Son espacios de juego que surgen de una idea democrática del espacio público, donde no hay especialización ni delimitación en cuanto a etapas vitales, evitando la segregación. Espacios con diferentes grados de complejidad que recorren diferentes estrategias proyectuales desde lo objetual a la construcción de un paisaje.

En esa secuencia del objeto al paisaje, la primera estrategia es aquella vinculada a la acción más sencilla, el diseño de objetos que, como juguetes de escala humana, modifican con su sola presencia las condiciones del contexto. Proyectos como las "Sculpture Aluminium Shells" que diseñó David Aaron (1957), objetos estáticos que buscan la diversidad de relaciones en una investigación que se centra en explorar todas las posibilidades de diseño de un mismo elemento u objetos que exploran la cualificación del lugar a través del movimiento. Un tiovivo o un columpio transforman la realidad donde se insertan, activando el lugar desde lo lúdico. "La residencia primordial del columpio es el exterior: la naturaleza transformada, el territorio convertido en lugar y la ciudad en cualquiera de sus versiones, en cualquiera de los recintos abiertos que propone para la estancia con el que el niño puede interactuar y que cualifican un lugar" (Parra, 2014). El proyecto de Ecosistemas Urbanos "Carrusel de Energía de Dordrecht", en Países Bajos (2010-2012), investiga ese registro integrando, además del juego, la generación de energía como recurso pedagógico.

Si los dos proyectos anteriores tenían una implantación fija en el lugar, el proyecto "Artefacto esta es mi plaza”, de las arquitectas de Conjuntos Empáticos (2019), explora las posibilidades de un artefacto efímero que, con reminiscencias de los proyectos de arquitectura neumática de Prada Pool, propone la activación de las plazas de Callao y Matadero, en Madrid, y Cal Comte de la Cova, en Palma, a través de un espacio lúdico, una especie de pompa de aire, un espacio interior que sumerge a niñas y niños en una atmósfera llena de color y posibilidades (Figura 9).

Figura 9. De izquierda a derecha, "Sculpture Aluminium Shells", Davis Aaron (1957), "Carrusel de energía de Dordrecht", Ecosistemas Urbanos (2010-2012) y

"Artefacto esta es mi plaza", Conjuntos Empáticos (2019)
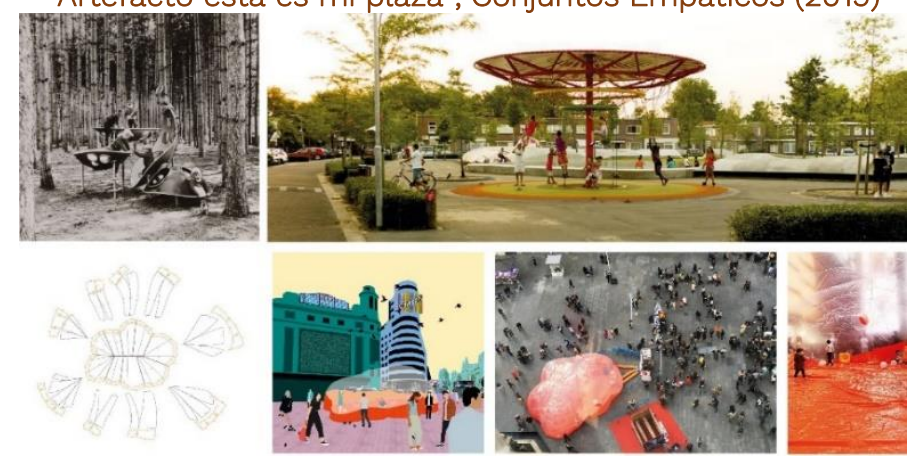

Fuente: De izq. a der., Aaron, D; Winawer, B.P. (1968). Child's Play: A Creative Approach to Playspaces for Today's Children. New York, USA: Harper \& Row. Sitio web de Ecosistemas Urbanos, sitio web Plataforma Arquitectura.

ACE, 16 (47) CC BY-ND 3.0 ES | UPC Barcelona, España | Paisajes infantiles. La infancia como constructora de un imaginario urbano. DOI: http://dx.doi.org/10.5821/ace.16.47.9945 
En un segundo grado de complejidad de las estrategias de proyectos vinculadas a los playgrounds se encuentran aquellas situaciones en las que una pequeña manipulación del plano del suelo cualifica y acota el espacio urbano, pero sin generar barreras ni límites, e incorpora el espacio infantil como un espacio público más. Dentro de esta estrategia estarían los playgrounds de Aldo van Eyck en Ámsterdam (1947-78). Una operación múltiple — se construyen hasta 700 espacios - que modificó la percepción del espacio público a través de pequeñas operaciones, en las que hay una huida explicita de la zonificación funcional. Van Eyck diseña espacios donde niñas y niños encuentran lugares que activan su imaginación, pero que, además, tienen la capacidad de congregar al resto de ciudadanos. En ese sentido, los proyectos desarrollados por M. Paul Friedberg en Nueva York durante los años 60 y 70 del pasado siglo (Tuset, 2019), tienen mucho en común con los espacios de Van Eyck. En primer lugar, ambos arquitectos modifican el espacio urbano a través de la construcción de una red de espacios públicos. Los proyectos de Van Eyck, cualificando espacios vacíos y en desuso ${ }^{11}$ resultado de los bombardeos de la Segunda Guerra Mundial en Ámsterdam. En el caso de Friedberg, convirtiendo en espacios públicos de calidad los espacios vacíos entre viviendas de las grandes promociones sociales del Nueva York de Robert Moses ${ }^{12}$ y los playgrounds de las escuelas públicas de Manhattan. Otra cualidad común es que detrás de los proyectos de ambos arquitectos hay una mujer: Jakoba Mulder, promoviendo la arquitectura de Van Eyck desde su puesto en el Departamento de Desarrollo Urbano de Ámsterdam, y Brook Astor como filántropa impulsora de los proyectos de Friedberg a través de su liderazgo en la Fundación Astor. En los espacios diseñados por ambos arquitectos también hay una reivindicación política de puesta en crisis del modelo capitalista de la ciudad de posguerra. En el caso holandés, esa crítica se hace desde las políticas del estado de bienestar europeo en proyectos de promoción pública. En el caso norteamericano, impulsado por la iniciativa privada.

En cuanto a la investigación arquitectónica, tanto Van Eyck como Friedberg consideran los parques de juego una oportunidad para rediseñar el espacio público como espacio de encuentro, que implica un posicionamiento sobre el plano del suelo. Van Eyck entiende este como un plano con diferencias topográficas mínimas, que evoca la imagen de la ciudad nevada ${ }^{13}$ como paradigma de la ausencia de zonificación funcional. Por su parte, Friedberg acuña el término "linked play", que implica al plano del suelo en la construcción, y lo entiende, más que como un espacio de juego, como un ambiente, en cuya configuración la generación de una topografía artificial será esencial. Sus proyectos exploran ese recurso, proyectando espacios donde una nueva topografía artificial hace imposible la diferenciación entre espacio y mobiliario. Todo contribuye a construir un nuevo paisaje urbano, gradas, colinas, espacios excavados, ambientes diferentes, pero conectados, que constituyen lugares de encuentro intergeneracional que convocan a todos los ciudadanos de la ciudad.

En sus proyectos como la plaza Riis en Jacob Riis Houses (1965) o Public School 166 Playground, Manhattan, Nueva York (1968) (Figura 10), el proceso de trabajo estará basado en una observación del contexto físico y funcional, y aprenderá tanto de las formas que encuentra en la ciudad como de los usuarios, convirtiendo a los niños y su forma de usar el espacio en su mayor inspiración. En este mismo sentido, las zonas de juego de Isamu Noguchi incorporan una componente estética, casi escultórica, que ofrece a su vez una oportunidad contemplativa a la comunidad y un trabajo que construye el espacio a través de la topografía y cuya influencia es decisiva en autores como Friedberg. En esta misma línea, y como transgresión del espacio de juego como obra artística, la plaza de los Fueros de Vitoria, de Chillida, se inserta en la ciudad como obra de arte funcional, lúdica y experimentable.

${ }^{11}$ Estos espacios suponían una "cesión temporal de uso" de terrenos en desuso. Una vez que los propietarios lo necesitaban, el espacio de juego desaparecía. Por ello, hoy día quedan poquísimos de estos espacios. Era una solución temporal que, con muy pocos recursos, solucionaba dos problemáticas: la falta de espacio para jugar y la problemática de los solares bombardeados o abandonados.

12 Especialmente significativo es el proyecto de la plaza Riis en Jacob Riis Houses, Nueva York, 1965, donde Friedberg desarrolla el diseño de un espacio público complejo en el que el espacio de juego infantil tiene continuidad total con el espacio público, relacionados a través de la sección. ${ }^{13}$ Aldo van Eyck hace referencia a esta idea en su artículo "When snow falls on cities", recogido en Ligtelijn y Strauven (2008). 
Figura 10. Proyectos M. Paul Friedberg. De izq. a der.: Sección e imágenes de Public School 166 Playground, Manhattan, N.Y., 1968. Croquis e imagen cenital plaza Riis, Jacob Riis Houses, N.Y., 1965
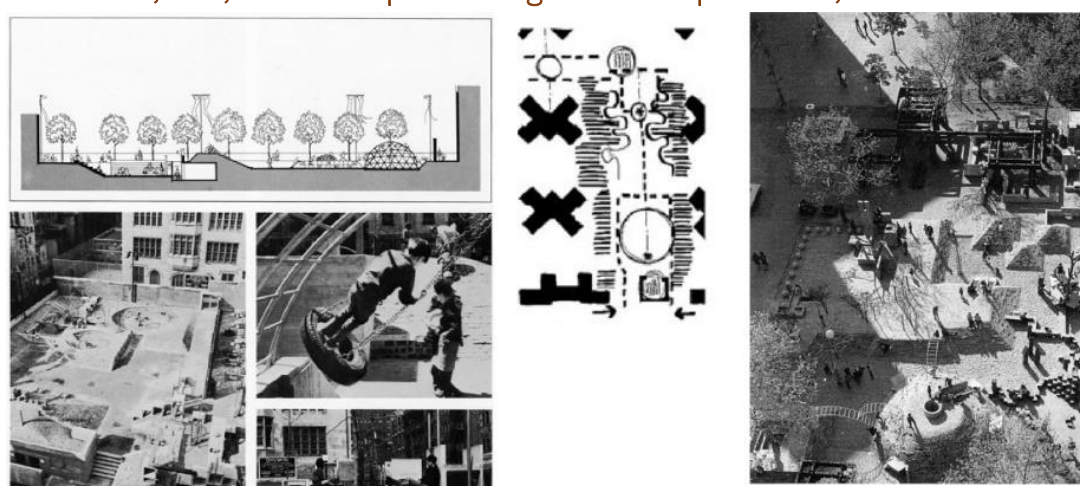

Fuentes: De izquierda a derecha Rouard, M. y Simon, J. (1976): D.; Vincent. Friedberg, M. P. (1989)

El trabajo de Friedberg (Vincent. Friedberg, M. P., 1989) o Noguchi constituyen un paso más en la generación de esos paisajes específicos que configuran los playgrounds. Aparecen entonces otros espacios que proponen un cambio de escala y que se acercan más al Land Art. Paisajes artificiales que incorporan la topografía como herramienta de delimitación espacial, con una gran carga estética, diluyéndose en el espacio urbano. Proyectos como los realizados por el paisajista Jacques Simon (Figura 11) aportan integración y mixtificación, además de generar paisajes urbanos que ofrecen más posibilidades tanto para sus usuarios como para la ciudad. Esos espacios abstractos trascienden de alguna forma el lugar específico de juego y ofrecen lugares a medio camino entre la instalación artística y una naturaleza recreada de formas orgánicas, que cualifican y ponen en valor grandes vacíos de la ciudad (Rouard, M. y Simon, J.,1976).

Figura 11. Patte d’Oie, Cité de la Croix Rouge, Reims. Mikado (J. Simon, 1971)

Fuente: Rouard, M. y Simon, J. (1976)

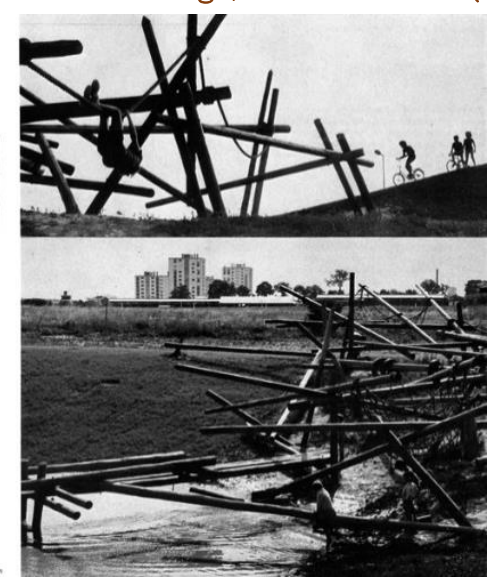

\subsection{Junks playgrounds o el ensayo de la ciudad ideal}

“Todos los problemas de la vida social presentan una elección entre soluciones libertarias y autoritarias, y la última reivindicación que podemos hacer del enfoque libertario es que es más eficiente, cumple mejor su función. El parque de aventuras es un ejemplo fascinante de esta anarquía viviente, valiosa tanto en sí misma como en la verificación experimental de todo el enfoque social" (Ward, 1961) ${ }^{14}$.

\footnotetext{
${ }^{14}$ Extracto del artículo, traducción de los autores. "All the problems of social life present a choice between libertarian and authoritarian solutions, and the ultimate claim we may make for the libertarian approach is that is more efficient - it fulfils its function better. The adventure playground is an arresting example of this living anarchy, one which is value both in itself and as an experimental verification of whole social approach".
}

ACE, 16 (47) CC BY-ND 3.0 ES | UPC Barcelona, España | Paisajes infantiles. La infancia como constructora de un 13 imaginario urbano. DOI: http://dx.doi.org/10.5821/ace.16.47.9945 
En este apartado se va a realizar un acercamiento a zonas de juego infantil generadas desde una postura de resistencia (Figura 12). En este caso, los playgrounds se entienden como acto y espacio de libertad de la infancia frente a la racionalización del mundo adulto: los conocidos como Junks Playgrounds (Europa), Adventure Playgrounds (Reino Unido), Junkjard Playgrounds (Estados Unidos), en los que se da un paso más a la hora de entender los juegos acotados de niñas y niños en la ciudad.

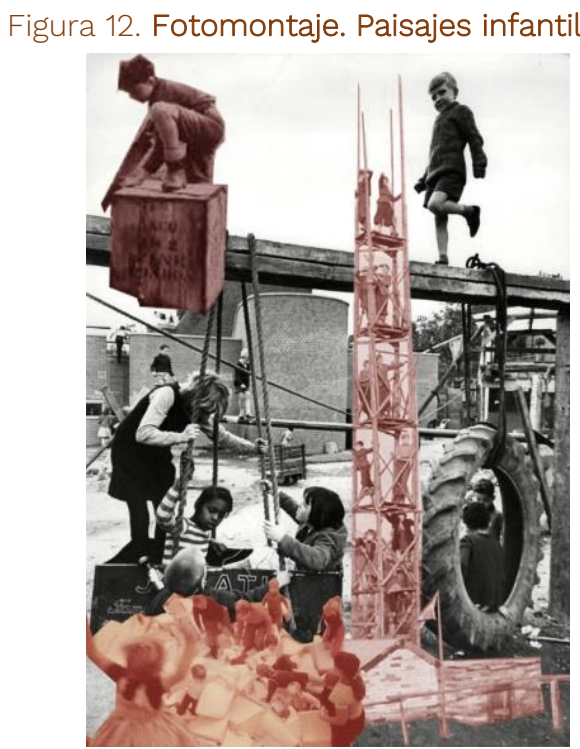

Fuente: elaboración propia. Fotomontaje realizado con las imágenes de Junks Playgrounds de Emdrup (Copenhague) y El Model, de Palle Nielsen.

En este caso, sí se trata de espacios delimitados físicamente, mediante un vallado ligero, y que normalmente se ubican en vacíos urbanos, abandonados, deteriorados o no urbanizados, pero donde se deja en manos de las niñas y los niños la construcción del espacio de juego. O sea, son ellas y ellos, con la manipulación de aquellos elementos de desecho que encuentran en el lugar, los que construyen parte del paisaje donde desarrollan sus juegos. Niñas y niños, por tanto, son usuarios y transformadores, y deciden dónde y cómo jugar. No existen elementos lúdicos predefinidos, sino materiales y herramientas, en su mayoría reutilizados, que pueden ser manipulados por ellos.

El primero de ellos, Emdrup, situado en Copenhague, abrió sus puertas en 1943 como reacción humanista y libertaria a la ocupación nazi. El parque se diseñó formando parte de un proyecto de más de 700 viviendas para familias numerosas, con una población inicial de casi 900 niñas y niños.

Los arquitectos paisajistas Carl Theodor Sørensen y Hans Dragehjelm, influenciados por la pedagogía de Friedrich Fröebel15, crean un espacio de juego siguiendo el leitmotiv "hágaselo usted mismo", convirtiendo así a los niños en arquitectos y maestros de sus propios juegos.

En el libro de Sorensen Parkpolitik i Sogn og Købstad' (1978), defiende su creencia de que los parques infantiles son la forma más importante de implantación pública de la ciudad, como espacio germen donde se producirán las nuevas reglas sociales después de la Segunda Guerra Mundial (Andersson y Hoyer, 2001). Emdrup (Figura 13) estaba lleno de materiales reciclados, recuperados por niñas y niños de entornos cercanos: madera, tuberías, cuerdas, lonas, ladrillos, neumáticos, troncos, pelotas, muebles abandonados, alambres y una variedad inimaginable de otras cosas, y cuyo aspecto le dio el nombre de skrammellegepladsen (juegos de basura).

\footnotetext{
${ }^{15}$ Hans Dragehjelm es el que introduce el método en Dinamarca, a través de la Fröebel Society en 1902, y elementos de juego al aire libre, como la caja de arena.

${ }^{16}$ Traducido como "Política del parque en la ciudad de la parroquia y del mercado".
} 
Figura 13. Emdrup, Carl Theodor Sørensen y Hans Dragehjelm, 1943
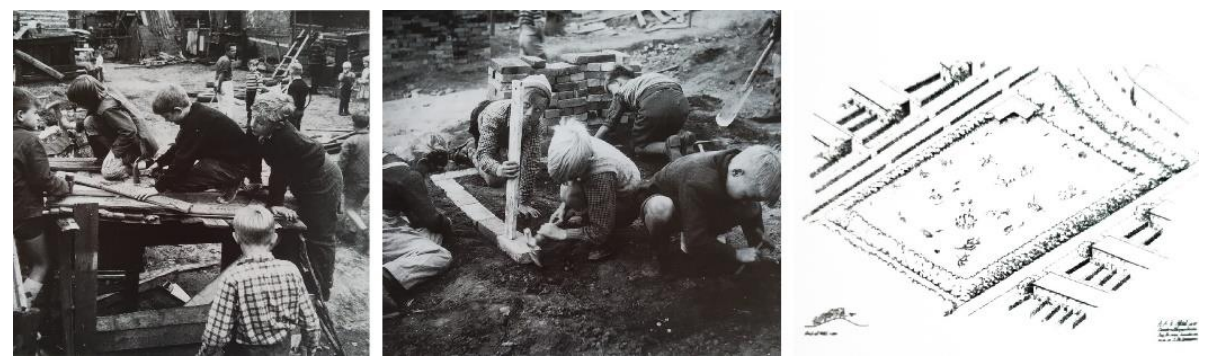

Fuente: Andersson, S. y Hoyer, S. (2001)

Se trataba de un espacio en transformación constante, barato y dinámico. Un espacio acotado intencionadamente, donde el límite adquiere una dimensión simbólica, ya que se construye para generar intimidad y protección de un espacio de libertad donde niñas y niños inventan y construyen su propia ciudad a salvo de los prejuicios y reglas de los adultos (García-González y Guerrero, 2019). Por tanto, lo que propone Emdrup es algo más que un nuevo programa lúdico para la infancia en la ciudad, es un manifiesto anarquista, tal y como defiende el pensador anarquista Colin Ward. Por un lado, es un espacio de aprendizaje alternativo a la escuela, que prepara a los niños para ser ciudadanos conscientes de su entorno construido. Por otro lado, es la posibilidad de que ellos mismos construyan ciudad, de forma libre, sin interferencias, solamente dirigidos por la figura del líder de juego, que se consolidará cuando este modelo se expanda por el resto de Europa y Estados Unidos. Una microciudad que surge muy influenciada por el pensamiento de Fröebel, como se ha visto, por su idea del aprendizaje en el espacio exterior y a través de la experimentación de la naturaleza, pero donde también se pueden rastrear otras corrientes pedagógicas, como el método Montessori, muy presente en los Países Bajos, donde el niño autogestiona su aprendizaje a través de la manipulación de los materiales que encuentra en el lugar. En este caso, materiales de desecho, con los que niñas y niños realizan un concienzudo trabajo que los capacita como constructores de una ciudad ideal, cercana a los ideales anarquistas de las vanguardias dadaístas (Moreno, 2020). El espacio de juego se transforma en una especie de ready made urbanos, consolidando los vacíos de la ciudad como laboratorio de experimentación y aprendizaje. Los junks playgrounds construyen una ciudad infantil alternativa, autogestionada, realizada con métodos cooperativos, donde no hay autoridad, que ensaya una sociedad democrática y propone un cierto activismo político de crítica a la ciudad funcionalista del movimiento moderno.

La extensión de este tipo de paisaje urbano por toda Europa se realizará de la mano de Lady Allen of Hurtwood, que de forma casi casual visita Emdrup. La paisajista británica supo ver en ese espacio una aplicación directa a los vacíos aparecidos en la ciudad de Londres tras los bombardeos de la II Guerra Mundial. Emdrup sienta las bases para los Adventure Playgrounds en Europa y América y el perfil de niñas y niños como diseñadores del espacio, como play workers.

Desde el citado primer espacio de juego danés, propuesto por Sorensen y Dragehjelm en Emdrup, Copenhague (1943), a su adaptación a los espacios vacíos bombardeados del Reino Unido de Joan Allen (1948), se produce una evolución crítica en el diseño de los espacios destinados a la infancia que acerca los playgrounds a lo casual, al azar de las vanguardias artísticas, y aporta una gran libertad para la construcción del paisaje y de la personalidad de sus usuarios, aspecto que se filtrará posteriormente en los procesos de participación social.

Esto también se pone de manifiesto en las propuestas artísticas de Palle Nielsen para el Moderna Museet de Estocolmo (1968) (Figura 14), donde ofrece un espacio dentro de un vacío, una sala de museo, donde los niños crean construcciones y reglas sociales a través del juego. Las niñas y los niños son personas usuarias y constructoras en un espacio que sirve de observación y reflexión para

ACE, 16 (47) CC BY-ND 3.0 ES | UPC Barcelona, España | Paisajes infantiles. La infancia como constructora de un 15 imaginario urbano. DOI: http://dx.doi.org/10.5821/ace.16.47.9945 
el artista, los visitantes del museo y para sacar conclusiones sobre qué modelo de educación se necesita para una sociedad cualitativa, en la línea que Huizinga propone.

Figura 14. The Model. Palle Nielsen, Moderna Museet de Estocolmo (1968) Imagen y planta del interior de la propuesta y planta

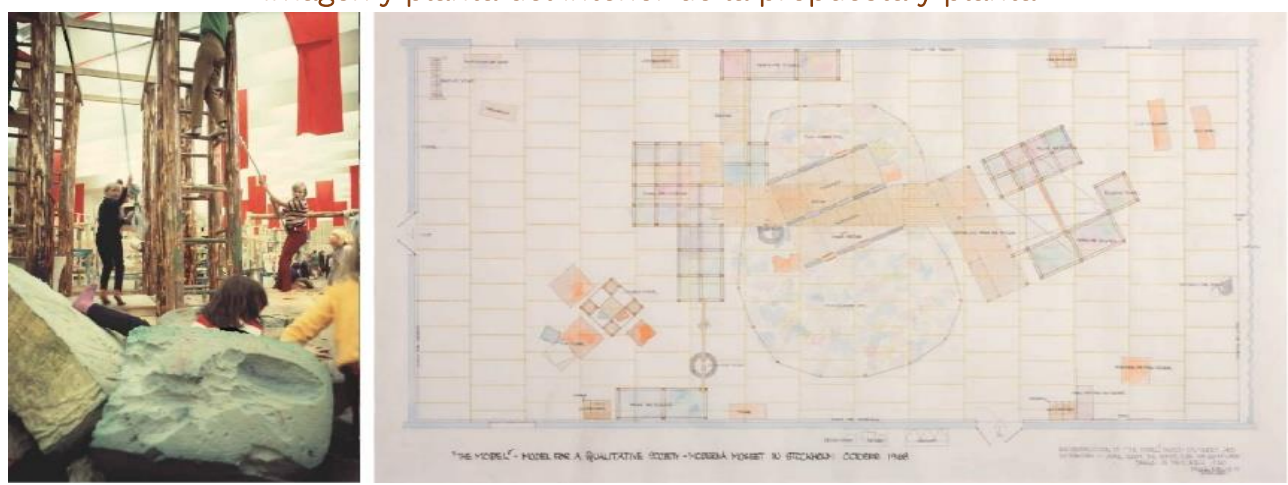

Fuente: Bang Larsen, L.; Nielsen P. (2010)

Se realiza una acción que quiere experimentar con la cultura social infantil fuera de la escuela, en un contexto artístico que propone otras herramientas para la creación de una nueva sociedad. El niño como sujeto, el juego como herramienta de aprendizaje y el espacio como entorno total de experimentación (Bang Larsen, L.; Nielsen P., 2010)

La situación lúdica que ideó y llevó a cabo Palle Nielsen (1920-2000) junto con Acción Diálogo, (plataforma ciudadana para la recuperación de espacios obsoletos en la periferia para el juego infantil en la ciudad), en el museo de arte moderno Moderna Museet de Estocolmo, bajo el nombre "El Modelo para una Sociedad Cualitativa”, planteaba aprovechar la acción infantil, lo inesperado, para modificar su comportamiento en aras de transformar la sociedad desde una nueva perspectiva. Ese modelo consiste en dar a niñas y niños lo necesario para que se desarrollen y vean la necesidad de cualificar su entorno y las relaciones con el mundo. Nielsen cree que para cambiar una sociedad es necesario modificar el propio comportamiento en las acciones cotidianas, lo que influirá en las relaciones y transformarán la sociedad. Se trataba de crear un espacio para la creatividad infantil y para reflejar la necesidad de interacción social. El espacio se iba transformando a medida que las niñas y los niños hacían uso de él. El proyecto consistía en una construcción en madera con escala suficiente para realizar actividades similares a los de un parque al exterior. En dicho espacio sonaba música rock, clásica, órgano y ruidos industriales sin parar, se colocaron cámaras que los mismos participantes dirigían y manipulaban y había todo tipo de materiales: pinturas, disfraces, caretas de líderes políticos, instrumentos, herramientas, neumáticos y cajas de cerveza. En el centro del espacio se dispusieron grandes bloques de gomaespuma de distintos tamaños a modo de puentes, torres o piscinas. El suelo estaba revestido con paneles de aglomerado, y las paredes con tableros de fibra blanda.

Posteriormente, el modelo salió fuera de la caja blanca y abstracta del museo y se trasladó a una nueva zona urbanizada, a las afuera de Västeras, al noroeste de Estocolmo. El parque se reconstruyó bajo una carpa, por lo que un niño la rebautizó como El Globo. La reflexión que traslada la experiencia del Modelo y los proyectos de los junks playgrounds se enlaza con la idea de que el tiempo que las niñas y los niños pasan jugando en el parque es una de las primeras experiencias que tienen en su contexto social. Según Nielsen, es un momento de libertad en el que el individuo tiene derecho a escoger sus propias relaciones sociales, donde pueden obviar las imposiciones o perfiles autoritarios, y favorecer acciones de cooperación. Es, por tanto, una oportunidad educativa más fuera del entorno escolar y familiar para crear futuros adultos más críticos y activos en la sociedad.

ACE, 16 (47) CC BY-ND 3.0 ES | UPC Barcelona, España | Paisajes infantiles. La infancia como constructora de un imaginario urbano. DOI: http://dx.doi.org/10.5821/ace.16.47.9945 


\subsection{Paisajes infantiles como paisajes de consumo}

En 1955, Walt Disney inauguró Disneyland en Anaheim, California, en un terreno de cultivo al sur de Los Ángeles. Este parque de atracciones es el pretexto para introducir la última categoría de espacio urbano contemporáneo diseñado para la infancia. Niñas y niños vuelven a ser protagonistas en el papel de usuario principal, en este caso como consumidor de una ciudad paralela a la ciudad real, diseñada para el placer y la diversión, dentro de un ideario puramente capitalista (Figura 15).

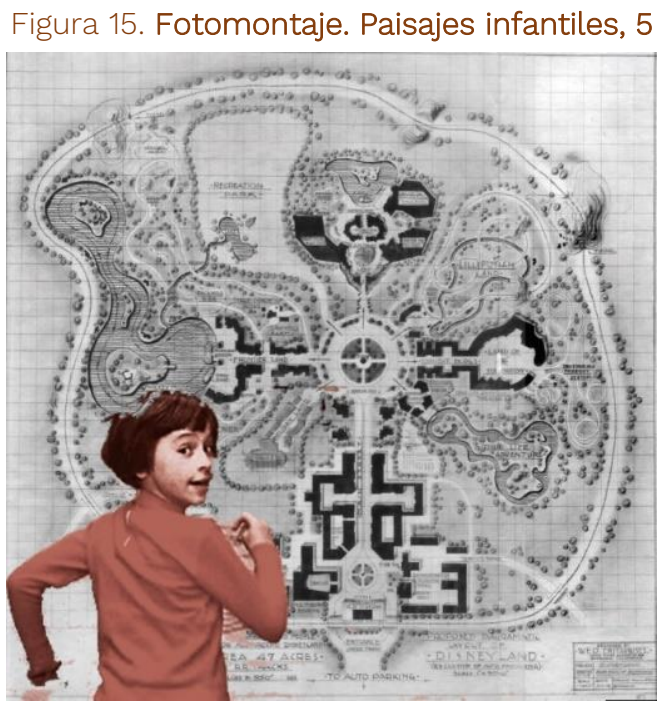

Fuente: Elaboración propia.

Si en los dos tipos de espacio anteriores, los playgrounds de posguerra o en los junks playgrounds, subyace una crítica férrea a la ciudad funcionalista y capitalista, este nuevo espacio desplaza al niño desde su posición de ciudadano a la de cliente, convirtiéndolo en personaje de una realidad prefijada.

Parece paradójico que la idea de Disneyland surgiera en la mente de su ideólogo a partir de dos situaciones que se podrían conectar con los espacios anteriormente estudiados, en un caso por similitud y en el otro por oposición. La primera de ella surge de la constatación de que los parques de juego a los que Disney acude con sus hijas son espacios excluyentes, ya que solo están pensados para la infancia. En ese sentido, hay una cierta idea de crítica a los espacios monofuncionales de la ciudad americana de posguerra, que también veíamos en los playgrounds, en su búsqueda de espacios intergeneracionales en la ciudad. Disney quiere crear un espacio para toda la familia, pero no para generar futuros ciudadanos críticos con la sociedad adulta, como proponía Van Eyck, sino adultos que se comporten como niños (bajo una idea del niño como adulto incompleto), eliminando toda la carga política de su ciudad ideal.

El otro hecho determinante en el mundo de Disney es la crítica puritana de su autor a los parques existentes en las ciudades, lugares a menudo sucios y peligrosos, donde las niñas y los niños no están a salvo. Esta idea es radicalmente opuesta a los junks playgrounds, que no esconden los desechos de la ciudad, que no protegen a la infancia, sino que la motivan para que generen su propio mundo.

Disneyland, como los junks playgrounds, es un recinto acotado. El límite en ambos casos es la separación de un mundo mágico interior del mundo real exterior, con la diferencia de que los segundos son espacios sucios, experimentales, peligrosos, lugares de aventuras que están por determinar. En Disneyland se recrea el mundo ideal de un hombre profundamente conservador, que materializa la expresión fantasiosa de la ciudad capitalista (Figura 16). Un espacio perfecto, diseñado

ACE, 16 (47) CC BY-ND 3.0 ES | UPC Barcelona, España | Paisajes infantiles. La infancia como constructora de un 17 imaginario urbano. DOI: http://dx.doi.org/10.5821/ace.16.47.9945 
para estimular el comportamiento compulsivo de sus visitantes, ofreciendo una cantidad ilimitada de mercancías y experiencias que lanzan a niñas, niños y adultos a una vorágine de consumo. Y que servirá de modelo para los futuros parques de atracciones.

Figura 16. Walt Disney mostrando la maqueta de Disneyland. 1957

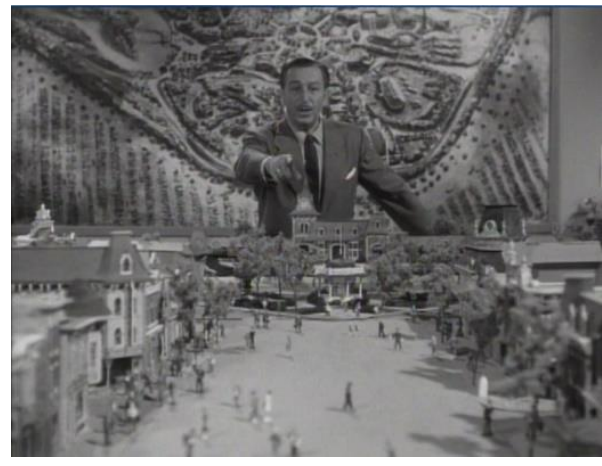

Fuente: Disney.

Disneyland es esa ciudad ideal que ofrece aquello que la ciudad real no puede dar a los ciudadanos (Moore, 1965). Un lugar donde todos los peligros de la ciudad real desaparecen: la suciedad, la pobreza, la lucha de clases. Un decorado que funciona como una máquina perfecta, pero donde todo lo que habla de su funcionamiento se oculta al visitante, incluso generando una ciudad alternativa, oculta y subterránea, por donde se mueven los trabajadores para realizar sus tareas sin ser vistos.

Como explica Francisco Javier Sánchez Merina en su tesis doctoral "Debates en la arquitectura anglosajona sobre el uso de la 'Historia'. Desde el Festival de Gran Bretaña (1951) a Disneyland París (1994)": "Por supuesto que Disneyland, a pesar de la habilidad y variedad de sus encantos, no ofrece toda la gama de experiencia pública. La experiencia política, por ejemplo, no se manifiesta aquí, y el lugar no pasaría nuestra prueba de revolución. Sin embargo, hay una variedad de formas y actividades lo suficientemente grande para asegurar una excelente oportunidad de que el visitante individual encuentre algo para identificarse". Y esa es una de las claves de su éxito, la ausencia de reflexión política que ofrece al visitante y la construcción de imaginarios con los que niñas, niños y adultos fácilmente se identifican. Una variedad de lugares que abarcan desde arquetipos urbanos como la Main Street, elemento principal articulador de este mundo ideal, hasta mundos pasados que son fácilmente identificables con el cine o la literatura, o incluso mundos futuros. Espacios donde los diseñadores de Disney juegan con la historia, de forma parecida a como lo harían más tarde los arquitectos posmodernos, y utilizan la infancia de nuevo como pretexto para crear otro tipo de paisaje urbano, pero ahora como una ciudad falseada y exaltación de la sociedad capitalista.

\section{El niño como agente transformador de la ciudad}

"El niño de hoy es preocupante, subversivo, revolucionario, porque es diferente de nosotros, los adultos: piensa de otra manera; ve las cosas de otra manera que no es errada sino solo diferente; vive sentimientos profundos, explosivos; tiene necesidades a menudo en conflicto con las nuestras. Tener en cuenta sus exigencias y sus ideas puede comportar profundas adaptaciones y renuncias en los adultos" (Tonucci, 2002).

Maria Montessori afirmaba que el niño era el maestro, y esa idea sirve para introducir el último registro que se va a explorar de la relación entre la infancia y la construcción de un paisaje urbano. Montessori habla de un cambio radical en la relación entre el maestro y el alumno, un cambio que en la pedagogía

ACE, 16 (47) CC BY-ND 3.0 ES | UPC Barcelona, España | Paisajes infantiles. La infancia como constructora de un 18 imaginario urbano. DOI: http://dx.doi.org/10.5821/ace.16.47.9945 
Montessori significa la autogestión del aprendizaje por parte de niñas y niños. Una situación donde este desempeña un papel activo y es el que determina qué, cuándo y cómo quiere aprender.

De la misma forma que desde la pedagogía, también desde el arte se ha modificado la mirada sobre el rol del niño, pasando de ser inspiración a ser considerado un verdadero artista objeto de estudio, como demuestra el trabajo realizado por Rhoda Kellogg en su "Child Art Collection", los murales colectivos realizados por el grupo CoBra con niñas y niños, o experiencias recientes y de carácter más local, como las que realiza el colectivo Tipi en el País Vasco bajo el nombre de "Educaciones", en que invitan a un artista local a realizar un trabajo colaborativo con estudiantes de primaria y secundaria.

Trasladando estas ideas a la ciudad, en este artículo, interesan aquellas situaciones que, por un lado, incorporan a la infancia al debate sobre lo urbano en un papel activo y, por otro lado, entienden el espacio público como el ambiente esencial para su aprendizaje. Cuestiones que ya estaban presentes en dos de los registros en la infancia como usuaria que se han analizado, en el 3.2 y en el 3.3, pero que aquí dan un paso más hacia el entendimiento de niñas y niños como agentes transformadores de la ciudad.

En ese sentido, es también paradigmática la película Zazie en el metro, basada en la novela homónima de Raymond Queneau (1959) y dirigida por Louis Malle en 1960. Podemos observar en ella también un cambio de papel del niño en la ciudad respecto a la película El globo rojo, analizada en el apartado 2.1 de este artículo. En la película de Malle, la niña Zazie también nos muestra París en una enloquecida deriva, pero en este caso la niña no se deja llevar por un agente externo, sino que tiene las ideas claras de lo que quiere y actúa en consecuencia, siendo ella la que parece decidir lo que hay que hacer en cada momento, por encima de la actitud errática y poco decidida de los adultos.

Figura 17. Proyecto educativo "Our City", Olga Adams. 1953

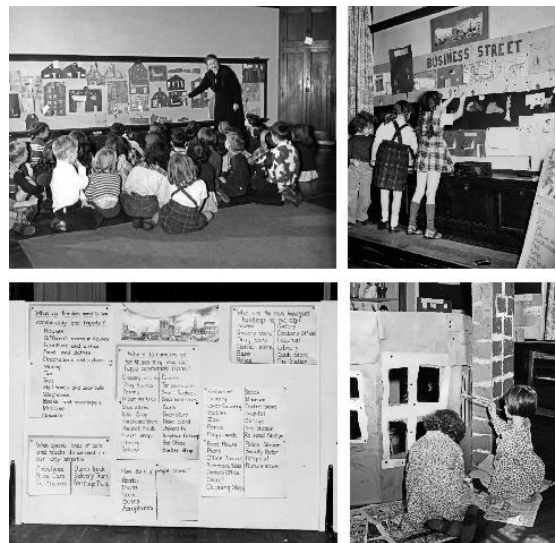

Fuente: Olga Adams Kindergarten and City Planning, Series II: Buildings and Grounds. Digital Collection University of Chicago

Un antecedente claro de ese nuevo papel de la infancia en la ciudad es el proyecto llamado "Our City" que la pedagoga Olga Adams (Figura 17) llevó a cabo en la década de 1950 en la Escuela Laboratorio de Chicago. El proyecto consistía en trabajar con los alumnos sobre su ciudad para que las niñas y los niños entendieran cómo funcionaba su entorno urbano. Los alumnos analizaban la ciudad donde vivían para más tarde desarrollar su propia idea de ciudad. Este trabajo no se quedaba solo en el análisis y en la propuesta, sino que los alumnos construyeron su propia ciudad de cartón y la gestionaron proponiendo nuevos modelos de autogestión. Este proyecto desembocó posteriormente en un grupo de planeamiento, al que se vincularon las niñas y los niños con voz propia en la ciudad. Esta visión transformadora de la infancia se apoya indiscutiblemente en la

ACE, 16 (47) CC BY-ND 3.0 ES | UPC Barcelona, España | Paisajes infantiles. La infancia como constructora de un 19 imaginario urbano. DOI: http://dx.doi.org/10.5821/ace.16.47.9945 
arquitectura: el espacio urbano se convierte, por tanto, en una intervención, en un acto de transformación no solo física, sino simbólica, del espacio antrópico.

Estas teorías tuvieron su continuidad en arquitectos que diseñaron equipamientos públicos destinados a la infancia, como escuelas o espacios de juego, sentando las bases de los actuales procesos participativos. Ejemplos claros de esto son las reuniones de Erskine con niñas y niños en su estudio para el diseño de la Escuela Gyttorp, Nora, Örebro County, Suecia (1959), o la participación de los futuros residentes que formaron parte del equipo de diseño como agentes activos en los concursos de cohousing del estudio Vandkunsten para la zona residencial del Tinggarden, al sudoeste de Copenhague (1971). El proyecto desarrollaría seis bloques residenciales con equipamientos colaborativos, cada uno de los cuales desarrollaba entre 12 o 17 apartamentos en diferentes tipos y un $10 \%$ de su superficie comunitaria destinada a espacios de socialización.

Dentro de esta línea de pensamiento cabe destacar el trabajo del pedagogo e ilustrador Francesco Tonucci que, continuando con las reflexiones de Van Eyck en su libro La ciudad de los niños (Tonucci, 2018), establece la necesidad de cambiar el punto de vista a la hora de la planificación de las ciudades, para lo que es necesario diseñarlas pensado en las necesidades de los más pequeños. Según Tonucci, una ciudad pensada para niñas y niños será una ciudad bien pensada para los adultos, afirmación que no es válida en sentido contrario. Esto implica diluir las actividades infantiles en la ciudad, evitando la delimitación de espacios específicamente por edades, dándole a niñas y niños un papel activo en ese proceso y favoreciendo su movimiento autónomo en la ciudad. Para Tonucci, las calles son peligrosas porque la invasión del espacio público por el coche provoca que no haya niñas y niños en ella. La desaparición de los coches favorecería que niñas y niños hicieran suyas las calles y no necesitarían los parques infantiles. Sus teorías se formalizaron en dos proyectos interesantes que hoy en día siguen vigentes: el primero de ellos es el realizado en su ciudad natal, Fano (1991), "La Ciudad de los niños", donde creó un comité infantil en el ayuntamiento para estudiar la ciudad desde las necesidades de la infancia, redefiniendo algunos parques y jardines y otros espacios públicos. El segundo es la definición de los "Caminos escolares", donde niñas y niños de seis a once años van solos a la escuela, considerando ese recorrido como una parte más de su aprendizaje. De este modo, hacen suya la calle, sin la estricta vigilancia de un adulto, y aprenden a respetarla como algo propio. De este recorrido autónomo por la ciudad no solo sacarán temas que contar en clase para madurar y encontrar la necesidad de aprender, será el alimento de la escuela y, por ende, también sentará las bases para generar una posición crítica en la construcción del paisaje urbano, generando un ciclo indispensable espacio público-aprendizaje-escuela que se retroalimenta.

Esta filosofía ha llegado a impulsar la inclusión en organismos internacionales la idea de que tener en cuenta a la infancia en el diseño de la ciudad es esencial. Iniciativas como la Asociación Internacional de Ciudades Educadoras (AICE) ${ }^{17}$, con más de 300 ciudades asociadas, o Ciudades Amigas de la Infancia, de Unicef, tratan de instrumentalizar estos procesos a través de acciones específicas, congresos, actividades de concienciación, etc. La incorporación de la infancia a la reflexión sobre cómo debe ser la ciudad no es más que un indicador de calidad de una nueva forma de ver la ciudad más inclusiva en relación con el género y la diversidad (García Ramón, Ortiz Guitart y Prats Ferret, 2014). En definitiva, una ciudad que sea diversa, integradora y sostenible, tal y como definen en su manifiesto el colectivo actual de arquitectas Equal Saree.

Otra experiencia muy interesante en este sentido es el proyecto educativo de la Escuela Riverside, de Kiran Bir Sethi, en Ahmedabad, que desde 2001 propone acciones urbanas como parte del

\footnotetext{
17 Uno de los escritos más importantes es "La carta de Ciudades Educadoras", creada en el I Congreso de Ciudades Educadoras en Barcelona en 1992, revisado y actualizado en diferentes congresos (Bolonia 1994, Génova 2004 y recientemente en 2020) para ir actualizándola a los nuevos retos sociales. Es el documento que recoge cuáles son los parámetros que debe tener una ciudad educadora. https://www.edcities.org/
} 
currículo. Esta escuela aprovecha el potencial del capital humano de sus alumnos y convierte a la escuela en verdadero laboratorio de investigación a nivel urbano. Bir Sethi aprovecha la capacidad pedagógica de la escuela para inocular mensajes de gran interés social, que sus alumnos luego retransmiten a pie de calle, ofreciendo otra dimensión de las excursiones escolares. Los alumnos trabajan temas de configuración urbana, como la eliminación de tráfico en distintas zonas de la ciudad o la peatonalización del espacio público. De este modo, no solo sirven de agentes educadores de la comunidad, sino que toman una posición activa en el proceso, al hacerse cargo de problemas locales, lo que les ofrece la posibilidad de generar una postura crítica sobre la configuración de su entorno.

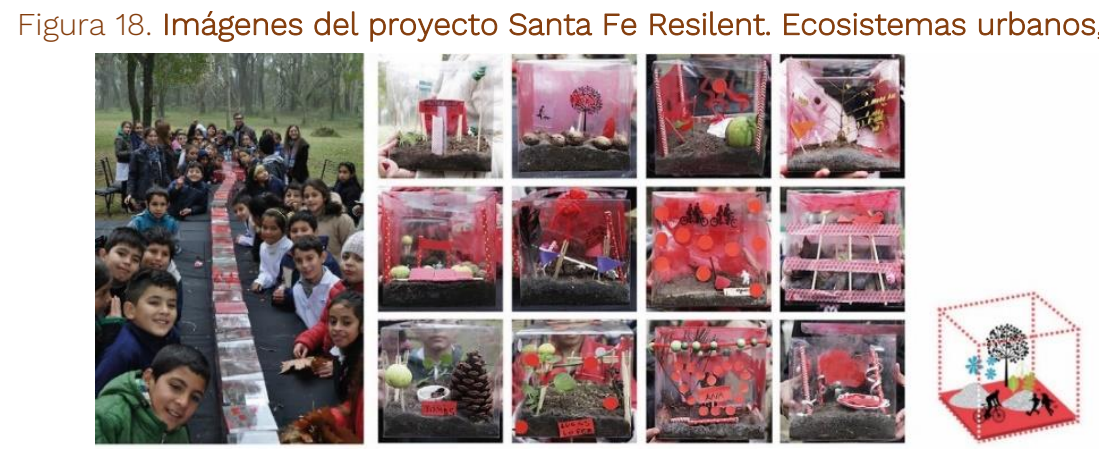

Fuente: Página web oficial de Ecosistemas Urbanos.

Las propuestas arquitectónicas comentadas anteriormente tienen su continuidad en otras actuales, como las realizadas por colectivos como Basurama, Zuloark, arquitectos como Javier Molinero o Ecosistemas Urbanos. Un proyecto especialmente interesante de Ecosistemas Urbanos es Santa Fe Resilent City, Argentina (2017) (Figura 18). Se trata de un encargo que surge en el contexto de programa de Estrategia de Resiliencia de la ciudad de Santa Fe. En este encargo, el equipo de arquitectos fue invitado a realizar una actividad participativa con niñas y niños de entre ocho y once años. El objetivo de la actividad era incorporar sus ideas en el proyecto del futuro parque del norte de Santa Fe. Para ello, se les propusieron tres acciones lineales en el tiempo. La primera: explorar y descubrir en la realidad actual del parque. A través de un paseo de exploración, se invitaba a niñas y niños a descubrir y observar el entorno natural donde se iba a actuar.

La segunda operación consistió en imaginar cómo sería su parque ideal, de modo que los niños expresaron sus pensamientos e ideas de lo que el parque podría ser. Todo esto se instrumentó a través de palabras clave, iconos y mapeos. La tercera acción fue crear su propio micropaisaje. Esta se implementó a través de unas maquetas, realizadas a partir de un kit de maqueta que se entregó a cada niño. Este kit consistía en una caja de metacrilato que cada niño debía rellenar con aquellos objetos y materiales encontrados en la naturaleza. Estos micropaisajes, elaborados, en principio, con los mismos componentes, generaron, sin embargo, unos micropaisajes específicos por cada niña o niño que participó en la actividad. Los micropaisajes elaborados por cada uno de los participantes se convertían en este proyecto en una herramienta consultiva creativa y progresiva, que integraba a niñas y niños en los procesos de diseño del espacio público de la ciudad.

Este proyecto y su metodología participativa parecen recoger los tres registros de la relación del niño y la ciudad recogidas en este artículo: su mirada, sus necesidades y sus opiniones.

Este cambio del papel del niño ha demostrado el gran potencial que tiene la visión transformadora de la infancia, y la valiosa implicación de la misma en el desarrollo de propuestas exitosas en cuanto a la construcción de un paisaje urbano sostenible y adaptado.

ACE, 16 (47) CC BY-ND 3.0 ES | UPC Barcelona, España | Paisajes infantiles. La infancia como constructora de un imaginario urbano. DOI: http://dx.doi.org/10.5821/ace.16.47.9945 


\section{Conclusiones}

Las propuestas analizadas desde la infancia ofrecen una visión de la ciudad que no fija un momento del tiempo, incorporándola en tres registros o papeles diferentes, el que mira y descubre nuevas realidades, el que genera nuevas formas de utilizar el espacio y el que propone una nueva ciudad: la infancia como inspiración, la infancia como usuaria y la infancia como transformadora de la ciudad. Niñas y niños, por tanto, como personajes centrales en todos los movimientos de vanguardia de los dos últimos siglos. Movimientos que han situado en lo periférico una nueva de forma de construir el paisaje, de lo observado a lo vivido, de lo vivido a lo trasformado, y han entendido que el espacio urbano es a la vez experiencia, transformación y aprendizaje dinámico de gran impacto en la memoria.

Para ello, se ha realizado el siguiente recorrido: en 2, "Miradas inspiradas en la infancia. Recorrer es aprender", se constataba la influencia que ha tenido y tiene la mirada infantil en nuestra cultura. Una idea que desplaza el pensamiento hacia el niño que todos fuimos y descubre en esa forma de mirar la posibilidad de poner en valor de nuevos lugares, otras realidades latentes y nuevas estrategias de transformación y aprendizaje. Una mirada desprejuiciada, creativa, basada en la experiencia, en la cual la herramienta fundamental en el aprendizaje será la acción de recorrer. En 3, "Paisajes específicos de la infancia", se analizan aquellos paisajes urbanos que han tenido a la infancia como origen de su reflexión. En 3.1, "Translaciones sobre el juego y el movimiento", se trabaja sobre estas dos ideas fundamentales para vincular el paisaje urbano con el aprendizaje infantil: el juego y el movimiento. En los siguientes tres puntos, 3.2, "Playgrounds como espacio público. Del objeto al paisaje", 3.3, "Junks playgrounds o el ensayo de la ciudad ideal" y 3.4, "Paisajes infantiles como paisajes de consumo", en el 3.2 se hace un recorrido por espacios específicos para la infancia que permiten la relación con el contexto y la integración de niñas y niños en el espacio público, pero sin que puedan alterar la realidad urbana en la que se insertan. La segunda propuesta se centra en unos espacios concretos, los junks playgrounds, espacios acotados de libertad, que, permiten que niñas y niños tengan un papel activo construyendo y trasformando el espacio de juego. Espacios que estimulan la fantasía, la autonomía, la creatividad, la disponibilidad para la acción y la autogestión. La tercera propuesta se centra en los parques temáticos, con Disneyland como espacio fundacional. Otro paisaje infantil que se sitúa en el extremo opuesto a los junks playgrounds, espacios también acotados que recrean un mundo de fantasía al margen de la ciudad, pero que tienen como modelo la ciudad americana capitalista, en que niñas y niños solo pueden desempeñar el papel de consumidores.

Desde este artículo se reivindican esas otras formas de hacer que se han fijado en la infancia para construir una forma alternativa de mirar, utilizar y transformar la ciudad, construyendo paisajes que tratan de superar el aislamiento funcional, social y cultural de la ciudad funcionalista. Paisajes urbanos que hablen de diversidad, integración y sostenibilidad, de participación, de lo cotidiano y lo humano como los aspectos esenciales para construir la ciudad.

En ese sentido, las mujeres han sido pioneras en esta reclamación. Activistas, arquitectas, sociólogas, pedagogas como Maria Montessori, Olga Adams, Jakoba Mulder, Brook Astor, Jane Jacobs, etc., han desempeñado un papel decisivo en la reflexión sobre de la infancia y la ciudad, abriendo el camino a que esta colaboración se lleve a cabo desde la autogestión y los órganos participativos locales, pero también a que se contemple esta perspectiva desde organismos oficiales locales, regionales, nacionales e internacionales.

Juego, recorrido, movimiento, espacios públicos como espacio de aprendizaje, coeducación, autogestión, participación, se convierten en palabras claves dentro de un discurso que habla de acciones y lugares que relacionan infancia y ciudad.

ACE, 16 (47) CC BY-ND 3.0 ES | UPC Barcelona, España | Paisajes infantiles. La infancia como constructora de un 
La infancia es entonces el símbolo del empoderamiento de lo periférico, de lo marginal, de los que no tienen poder de decisión sobre lo urbano, reivindicándola como agente necesario para cambiar la forma de hacer ciudad.

\section{Autoría}

La primera autora ha conceptualizado y diseñado la investigación, ha escrito parte del trabajo, ha realizado la revisión bibliográfica, la selección de casos de estudio e imágenes, así como ha realizado las revisiones del artículo; la segunda autora ha conceptualizado y diseñado la investigación, ha escrito parte del trabajo, ha diseñado los fotomontajes de la investigación; el tercer autor ha conceptualizado y diseñado la investigación, ha escrito parte el trabajo, ha realizado la búsqueda y análisis de los casos de estudio.

Conflicto de intereses: Los autores declaran que no hay conflicto de intereses.

\section{Bibliografía}

Andersson, S. y Hoyer, S. (2001). C. Th. Sorensen: landscape modernist. Copenhague, Dinamarca: The Danish Architectural Press.

Bang Larsen, L.; Nielsen P. (2010). El model Un model per a una societat qualitativa (1968). Barcelona, Cataluña: MACBA. Recuperado en: https://img.macba.cat/public/document/2020-04/palle-nielsendobles-cat.pdf

Careri, F. (2014). Walkscapes. El andar como práctica estética. Barcelona, España: Gustavo Gili

García-González, M. C., \& Guerrero, S. (2019). Sobre el espacio de juego infantil en la ciudad moderna: Lady Allen of Hurtwood versus Jakoba Mulder. Ciudad Y Territorio Estudios Territoriales, 51(200), 311326. Recuperado a partir de https://recyt.fecyt.es/index.php/CyTET/article/view/76733

García Ramón, M. D.; Ortiz Guitart, A. y Prats Ferret, M. (2014). Espacios públicos, género y diversidad. Barcelona, España: Icaria.

Gehl, J. (2015). Ciudades para la gente. Buenos Aires, Argentina: Ediciones Infinito.

Gisboure, M.; Kukudielka, R. y Djerassi, C. (2008). Paul Klee: la infancia en la edad adulta: [Catálogo de la exposición] Centro Atlántico de Arte Moderno, las Palmas de Gran Canaria, 19 de octubre de 20075 de enero de 2008. Las Palmas de Gran Canarias, España: Centro Atlántico de Arte Moderno.

Gros, F. (2014). Andar. Una filosofía. Barcelona, España: Taurus.

Huizinga, J. (2012). Homo ludens. Barcelona, España: Alianza Editorial.

Jacobs, J. (2011). Muerte y vida de las grandes ciudades. Madrid, España: Capitán Swing.

Kinchin, J. y O'Connor, A. (2012). Century of the Child: Growing by Design, 1900-2000. Nueva York, USA: Museum of Modern Art.

Ligtelijn V. y Strauven, F. (2008). Aldo van Eyck. Writings. Ámsterdam, Holanda: Sun, cop.

Llorca J. (2021). Aporías de la investigación en arquitectura: adaptación del modelo científico en la producción y divulgación del conocimiento explícito. ACE. Arquitectura, ciudad y entorno, (46). Recuperado de DOI: https://doi.org/10.5821/ace.16.46.9531

Mayoral-Campa, E. (2014). Pensamientos Compartidos. Aldo van Eyck, el grupo COBRA y el arte. Proyecto, Progreso, Arquitectura, (11), 64-75.

ACE, 16 (17) CC BY-ND 3.0 ES | UPC Barcelona, España | Paisajes infantiles. La infancia como constructora de un 23 imaginario urbano. DOI: http://dx.doi.org/10.5821/ace.16.47.9945 
Recuperado de https://doi.org/10.12795/ppa.2014.111.05

Moore, C. W. (1965). You have to pay for the public space. Perspecta, (9-10). Recuperado de https://placesjournal.org/article/you-still-have-to-pay-for-the-public-life/?cn-reloaded=1

Moreno, J. C. (2020). Del ready-made al playground: el desplazamiento de la función como estrategia política. REIA, (15). Recuperado de http://www.reia.es/REIA15 08 WEB.pdf

Morris, W. (1908). Hopes and fears of art. Londres, Inglaterra: Longman Green and Co.

Muntaner, J. J. (2009). Consecuencias didácticas de la Teoría de J. Piaget. Enseñanza \&Amp;

Teaching: Revista Interuniversitaria De Didáctica, (6). Recuperado a partir de https://revistas.usal.es/index.php/0212-5374/article/view/3442

Navarro, V. (2013). Playgrounds del siglo XXI. Una reflexión sobre los espacios de juego de la infancia. Arquitectonics: mind, land \& society, (25).

Parra, J. J. (2014). Impeler columpios o la leve arquitectura de la acción. RE/A, (2), 127-148. Recuperado de http://reia.es > REIA208

Perec, G. (2013). Lo infraordinario. Buenos Aires, Argentina: Eterna Cadencia Editores, 2013.

Pozo-Bernal, M. y Mayoral-Campa, E. (2016). Espacio itinerante. La intermitencia espacio-temporal del conocimiento. International Conference Arquitectonics Network: Mind, Land and Society, Barcelona, 1-3 June 2016: Final papers. Barcelona, España: GIRAS. Universitat Politècnica de Catalunya. Recuperado de http://hdl.handle.net/2117/106506

Rouard, M. y Simon, J. (1976). Espaces de jeux: de la boîte à sable au terrain d'aventure. París: D. Vincent.

Sánchez Merina, F. J. (2002). Debates en la arquitectura anglosajona sobre el uso de la "Historia". Desde el Festival de Gran Bretaña (1951) a Disneyland París. (Tesis Doctoral). Universitat Politècnica de Catalunya, Barcelona. Recuperado de http://hdl.handle.net/10803/6076

Sánchez Llorens, M. (2015). Lina Bo Bardi, objetos y acciones colectivas. Buenos Aires, Argentina: Diseño Editorial.

Tuset Davó, J. J. (2019). M. Paul Friedberg: escenografías para el juego en hábitats urbanos. BAC Boletín Académico. Revista de Investigación y Arquitectura Contemporánea, 9, 23-44. Recuperado de DOI: https://doi.org/10.17979/bac.2019.9.0.4638

Tonucci, F. (2002). Cuando los niños dicen ibasta! Madrid, España: Fundación Germán Sánchez Ruipérez.

Tonucci, F. (2018). La ciudad de los niños. Barcelona, España: Grau.

Vergara, A.; Peña, M., Chávez, P. y Vergara, E. (2013). Los niños como sujetos sociales: el aporte de los nuevos estudios sociales de la infancia y el análisis crítico del discurso. Psicoperspectivas, Individuo y Sociedad, 14(1), 55-65. Recuperado de https://www.psicoperspectivas.cl/index.php/psicoperspectivas/article/view/544

Vincent. Friedberg, M. P. (1989). Landscape Design. Tokio, Japón: Process Architecture.

Ward, C. (1961). Adventure Playgrounds: A Parable of Anarchy. Anarchy, (7), 193-201. Recuperado de http://libcom.org/files/Colin-Ward-reader.pdf

Ward, C. (1978). The child in the city. Londres, UK: The Architectural Press Ltd. 